\title{
Results of a CCPR Intercomparison of Spectral Irradiance Measurements by National Laboratories
}

\begin{tabular}{ll}
\hline Volume 96 & \multicolumn{1}{c}{ Number 6} \\
\hline James H. Walker, Robert D. & $\begin{array}{l}\text { An intercomparison of spectral irradi- } \\
\text { ance measurements by } 12 \text { national labo- } \\
\text { ratories has been carried out between } \\
\text { Saunders, John K. Jackson, and and 1990. The intercomparison } \\
\text { Klaus D. Mielenz }\end{array}$ \\
$\begin{array}{l}\text { National Institute of Standards } \\
\text { the Comite Consultatif de Photometrie } \\
\text { and Technology, }\end{array}$ & $\begin{array}{l}\text { et Radiometrie (CCPR) of the Comité } \\
\text { International des Poids et Mesures, and } \\
\text { the National Institute of Standards and } \\
\text { Technology (NIST) served as the pilot } \\
\text { laboratory. The spectral range of the } \\
\text { intercomparison was 250 to 2400 nm } \\
\text { and the transfer standards used were } \\
\text { commercial tungsten-halogen lamps of } \\
\text { two types. The world-wide consistency } \\
\text { of the results (one standard deviation) }\end{array}$
\end{tabular}

November-December 1991

was on the order of $1 \%$ in the visible spectral region and 2 to $4 \%$ in the ultraviolet and infrared portions of the spectrum. The intercomparison revealed no statistically significant differences between spectral-irradiance scales based on blackbody physics and absolute detector radiometry.

Key words: CCPR; intercomparison; national laboratories; radiometry; spectral irradiance; tungsten-halogen lamps.

Accepted: August 28, 1991

\section{Overview}

At the September 1986 Session of the Comite Consultatif de Photometrie et Radiometrie (CCPR) of the Comité International des Poids et Mesures [1], the delegates of the National Institute of Standards and Technology (NIST) proposed an intercomparison of the spectral-irradiance scales maintained and disseminated by national standards laboratories throughout the world. The proposal received wide support and the Radiometric Physics Division of NIST was appointed the pilot laboratory for the intercomparison. It was agreed that the intercomparison would cover the spectral region from 250 to $2400 \mathrm{~nm}$, and that the following scledule would be adhered to:

1987/88 - Invitation to participants, procurement of intercomparison lamps, lamp mounts, and alignment jigs.
1989/90 - Initial calibration of a set of three lamps by each participant, calibration of all lamps by NIST, and repeat calibration of each set of lamps by the participants.

The intercomparison was to be "blind," in that the NIST results would not be revealed to the participants until their repeat calibrations had been completed.

A preliminary NIST report of the intercomparison was presented at the September 1990 Session of the CCPR [2]. The committee decided to allow no more "fine tuning" of data, and appointed a working party convened by NIST to prepare a final report in which the results of the intercomparison are presented in terms of the differences, 


$$
r=\begin{aligned}
& \text { Average of "before" and "after" } \\
& \frac{\text { measurements by participants }}{\text { NIST measurement }}-1 \text {. }
\end{aligned}
$$

This value was multiplied by 100 to obtain the percent difference from NIST. It was noted that the quotients in Eq. (1) are reciprocal to the equivalent quotients used in the 1975 spectral-irradiance intercomparison coordinated by the Electrotechnical Laboratory (ETL) of Japan [3] and that in the latter intercomparison the final data were adjusted to show the differences of each participant (including ETL) from a "world mean" of zero.

\section{Participants}

Twelve national laboratories participated in the intercomparison. ${ }^{1}$ They are listed below, with the names of the principal investigators assigned to the intercomparison given in parentheses.
CSIRO - Commonwealth Scientific and Indus- trial Research Organization, Division of Applied Physics, Lindfield, Aus- tralia (J. L. Gardner).
ETL - Electrotechnical Laboratory, Ibaraki, Japan (M. Nishi).
INM - Institut National de Metrologie du Conservatoire National des Arts et Metieres, Paris, France (J. Bastie).
IOM - Instituto de Optica Daza de Valdes, Madrid, Spain (A. Corrons).
NIM - National Institute of Metrology, Bei- jing, People's Republic of China (Chen Xiaju).
NIST - National Institute of Standards and Technology, Gaithersburg, MD, USA (J. H. Walker).
NPL - National Physical Laboratory, Teddington, Middlesex, UK (J. R. Moore).

DPT - Division of Production Technology, CSIR, Pretoria, South Africa (F. Hengstberger).

NRC - National Research Council, Ottawa, Canada (L. P. Boivin).

\footnotetext{
'Data submitted by the Amt fuer Standardisierung, Messwesen und Warenpruefung (ASMW) of the former German Democratic Republic were withdrawn after the unification of Germany.
}
$\mathrm{OMH} \quad-$ National Office of Measures, Bu- dapest, Hungary (G. Deszi).

PTB - Physikalisch-Technische Bundesanstalt, Braunschweig, Federal Republic of Germany (J. Metzdorf)

$\begin{aligned} \text { VNIIOFI - } & \text { All-Union Research Institute of Op- } \\ & \text { tical and Physical Measurements, } \\ & \text { Moscow, U.S.S.R. (V. I. Sapritsky). }\end{aligned}$

\section{Lamps}

The lamp originally chosen for the intercomparison was a $770 \mathrm{~W}(14 \mathrm{~A}$ at $55 \mathrm{~V}$ dc) tungstenbromine lamp that had been developed jointly by the National Physical Laboratory (NPL) and the General Electric Company (GEC) of the United Kingdom for use both as a standard of spectral irradiance and as a standard of illuminance at a cor-

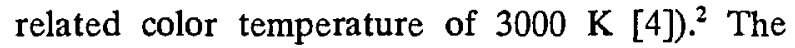
filament assembly of the lamp, consisting of six vertical tungsten coils arranged in a $16 \times 24 \mathrm{~mm}$ plane, is enclosed in a fused-silica envelope filled with 304 $\mathrm{kPa}(3 \mathrm{~atm})$ of nitrogen (equivalent to $1013 \mathrm{kPa}(10$ atm) when the lamp is operating). The lamp is equipped with a commercial $22 \mathrm{~mm}$ bi-pin base and is operated base down. Initial testing at the NPL had shown that the lamp required aging for 300 to $400 \mathrm{~h}$ on dc in order to achieve a stability in illuminance of no worse than $0.5 \%$ per $100 \mathrm{~h}$ of use. The lamp obeyed the inverse-square law for working distances greater than $200 \mathrm{~mm}$. Its uniformity of field was found to be better than $\pm 0.5 \%$ over an angular range of $5^{\circ}$ subtended at the lamp in the direction of a horizontal axis through the center of, and perpendicular to, the filament plane.

NPL had agreed to select and deliver three of these NPL/GEC lamps for each participating laboratory. This was achieved in mid-1988, but unfortunately some of these lamps failed during the first round of measurements and replacements could no longer be obtained from GEC. In order to remedy this difficulty, NIST supplied several of its routinely issued spectral-irradiance standard lamps (General Electric Company (USA) FEL lamps) to

\footnotetext{
${ }^{2}$ Certain commercial equipment, instruments, or materials are identified in this paper to specify adequately the experimental procedure. Such identification does not imply recommendation or endorsement by the National Institute of Standards and Technology, nor does it imply that the materials or equipment identified are necessarily the best available for the purpose.
} 
those laboratories that had lost NPL/GEC lamps or wished to include the NIST/FEL lamp for other reasons.

A detailed description of the NIST/FEL lamp may be found in Ref. [5]. The lamp, rated at $1000 \mathrm{~W}$, is a clear quartz envelope, tungsten-halogen lamp with a cylindrical coiled-coil filament of 8 $\mathrm{mm}$ diameter and $24 \mathrm{~mm}$ height. The lamp is modified to a $22 \mathrm{~mm}$ bi-pin base and is operated base down. The lamps are annealed at $120 \mathrm{~V}$ dc for $40 \mathrm{~h}$ (13\% of its rated life), and then burnt in for $24 \mathrm{~h}$ under normal operating conditions (7.7 to $8.0 \mathrm{~A}$ at 106 to $112 \mathrm{~V} \mathrm{dc}$ ) to test their stability. Only lamps with changes less than $0.5 \%$ in $24 \mathrm{~h}$ at $655 \mathrm{~nm}$ are accepted. All lamps are tested for irradiance uniformity over a $+1^{\circ}$ range of rotation and tilt, and lamps exhibiting changes greater than $1 \%$ are rejected.
Schematic drawings of the NPL/GEC and NIST/ FEL lamps are shown in Fig. 1. NIST supplied alignment jigs and detailed alignment instructions for each lamp type. The lamps were to be mounted vertically, base down, and measured at a distance of $500.0 \mathrm{~mm}$ between a specified reference plane and the aperture of the receiving instrument. The average spectral irradiances (in $\mu W / \mathrm{cm}^{2} / \mathrm{nm}$ ) produced by the lamps under these conditions are plotted in Fig. 2. From these data it was estimated that the approximate correlated color temperatures of the lamps were $2979 \mathrm{~K}$ for the NPL/GEC lamps and $3075 \mathrm{~K}$ for the NIST/FEL lamps.

The final count of lamps used in the intercomparison was 25 NPL/GEC lamps and 6 NIST/FEL lamps. Most participants contributed data for three lamps. Two laboratories (ETL, VNIIOFI) contributed data for two lamps.
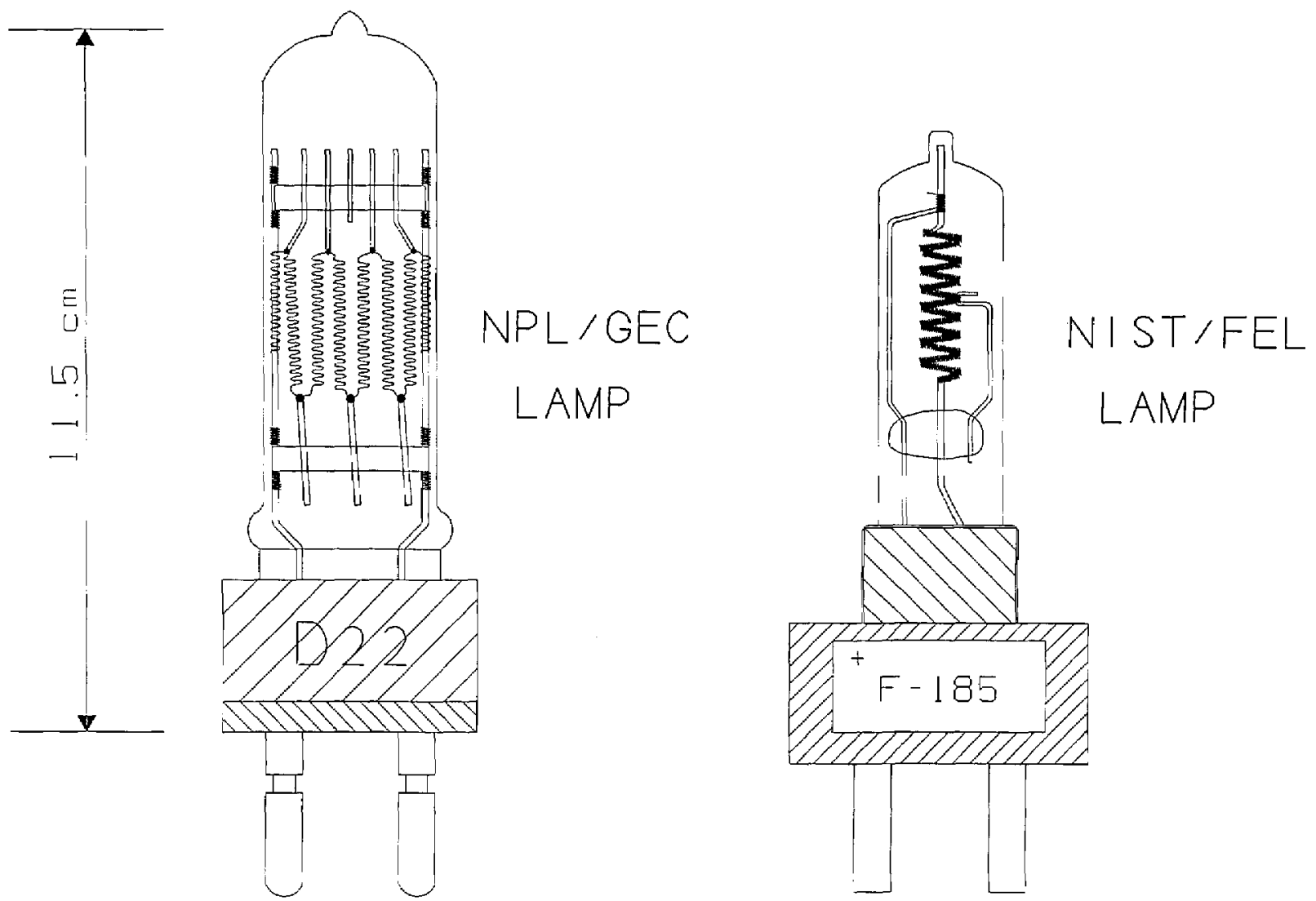

Figure 1. Lamps used in the spectral irradiance intercomparison. 


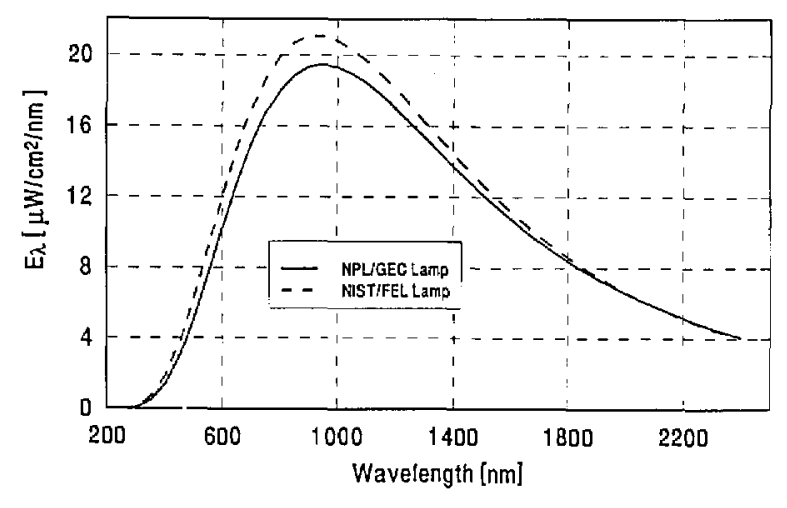

Figure 2. Average spectral irradiances of NPL/GEC and NIST/ FEL lamps at a distance of $50 \mathrm{~cm}$ from lamp.

\section{Measurement Procedures at Partici- pating Laboratories}

All lamps were operated at a constant current and their voltage was monitored. All the NPL/GEC lamps were operated at $14.000 \mathrm{~A}$ with a nominal voltage of about $55 \mathrm{~V}$. The NIST/FEL lamps were operated at either $7.700,7.800$, or $7.900 \mathrm{~A}$ with nominal voltages of 106 to $109 \mathrm{~V}$.

The information provided by the participating laboratories on the measurement methods used by them may be found in Appendix A of this paper. This information is summarized in Table 1, and the following points are worth emphasizing.

(a) Six laboratories (ETL, INM, NIM, NIST, PTB, VNIIOFI) had independently realized their spectral-irradiance scales by blackbody physics. All of these scales were stated to be consistent with the International Temperature Scale of 1990 [6] that was adopted during the intercomparison. Two scales (IOM, DPT) and the infrared portion of another (NRC from $700 \mathrm{~nm}$ upwards) had been independently realized by electrically calibrated radiometers. Two laboratories (CSIRO, NPL) reported that the 350 to $800 \mathrm{~nm}$ portions of their scales were based on relative spectral distributions derived from blackbodies, with absolute values assigned by photometric measurements. The NPL ultraviolet scale below $370 \mathrm{~nm}$ was based on synchrotron radiation. The NPL infrared scale from $900 \mathrm{~nm}$ upwards was based on provisional calculations using published data for the emissivity of tungsten because their new infrared scale was not completed in time for the intercomparison. The remaining scales (CSIRO below $350 \mathrm{~nm}$ and above $800 \mathrm{~nm}$, NRC from 300 to $700 \mathrm{~nm}$,
OMH) were based on transfer standards provided by other national laboratories.

(b) Most laboratories contributed data over significant portions of the uv, visible, and near ir, but only five laboratories (CSIRO, ETL, NIM, NIST, PTB) covered the entire 250 to $2400 \mathrm{~nm}$ intercomparison range.

(c) All laboratories used medium-sized ( 0.25 to 1 $\mathrm{m}$ focal length) spectroradiometers. All used S-20 type photomultiplier tubes for measurements in the uv and visible. The detectors used in the infrared were Si and Ge photodiodes or $\mathrm{PbS}$ photoconductive cells, and several laboratories used two of these detectors.

(d) All laboratories performed the measurements using routine calibration methods and procedures. However, most laboratories performed the measurements using highly qualified staff and special care. Tests of wavelength accuracy, stray radiant energy, detector linearity and ambient temperature were performed as a routine matter.

All laboratories were requested to provide one standard deviation estimates of their measurement uncertainty, with random and systematic errors added in quadrature. These estimated uncertainties are listed in Table 2.

\section{Measurement Procedure at NIST}

The spectral irradiance measurements performed at NIST were made relative to the 1990 NIST scales of thermal radiometry [7] and are fully consistent with the ITS-90. Before and after spectral irradiance measurements on all intercomparison lamps were performed, once in September/ October 1989 and again in April/May 1990, the NIST spectral irradiance scale was realized by calibrating a group of nine NIST/FEL transfer standards against a gold-point blackbody standard, using the measurement procedures described in Refs. [5] and [7]. All NIST measurements contributed to the intercomparison were derived by linear interpolations between these two scale realizations. The measurement setup used to compare the participants' intercomparison lamps to the NIST transfer standards is shown in Fig. 3. Each intercomparison lamp was measured against each of four NIST/FEL transfer standards, and the four spectral-irradiance values thus obtained for each lamp were averaged. The total burning time at NIST was on the order of 20 to $25 \mathrm{~h}$ for each lamp. A more detailed description of the NIST measurements may be found in Appendix A. 
Table 1. Summary of measurement conditions at participants' laboratories

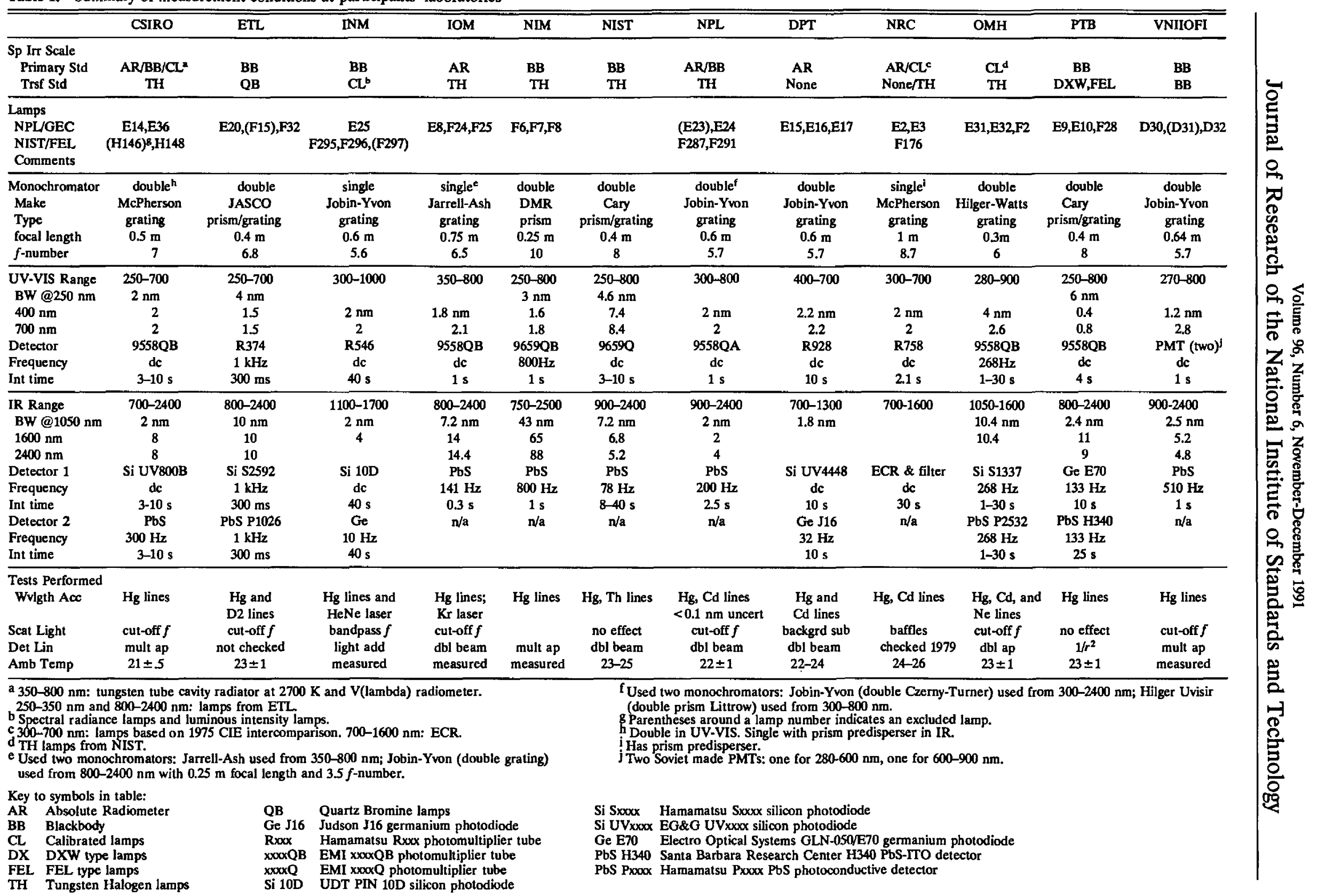


Table 2. Grand-mean percent differences ${ }^{\mathrm{a}}$ from NIST and estimated one standard deviation uncertainties of participants' measurements

\begin{tabular}{|c|c|c|c|c|c|c|c|c|c|c|c|c|c|c|c|c|c|c|c|c|c|c|c|}
\hline \multirow[b]{2}{*}{$\begin{array}{l}\text { WL } \\
(\mathrm{nm})\end{array}$} & \multirow{2}{*}{$\begin{array}{l}\text { NIST } \\
\text { Unc } \\
(\%)\end{array}$} & \multicolumn{2}{|c|}{ CSIRO } & \multicolumn{2}{|c|}{ ETL } & \multicolumn{2}{|c|}{ INM } & \multicolumn{2}{|c|}{ IOM } & \multicolumn{2}{|c|}{ NIM } & \multicolumn{2}{|c|}{ NPL } & \multicolumn{2}{|c|}{ DPT } & \multicolumn{2}{|c|}{ NRC } & \multicolumn{2}{|c|}{ OMH } & \multicolumn{2}{|c|}{ PTB } & \multicolumn{2}{|c|}{ VNIIOFI } \\
\hline & & $\begin{array}{r}\text { Grand } \\
\text { mean }\end{array}$ & $\begin{array}{l}\text { Unc } \\
(\%)\end{array}$ & $\begin{array}{c}\text { Grand } \\
\text { mean }\end{array}$ & $\begin{array}{l}\text { Unc } \\
(\%)\end{array}$ & $\begin{array}{l}\text { Grand } \\
\text { mean }\end{array}$ & $\begin{array}{l}\text { Unc } \\
(\%)\end{array}$ & $\begin{array}{c}\text { Grand } \\
\text { mean }\end{array}$ & $\begin{array}{l}\text { Unc } \\
\text { (\%) }\end{array}$ & $\begin{array}{l}\text { Grand } \\
\text { mean }\end{array}$ & $\begin{array}{l}\text { Unc } \\
(\%)\end{array}$ & $\begin{array}{l}\text { Grand } \\
\text { mean }\end{array}$ & $\begin{array}{l}\text { Unc } \\
(\%)\end{array}$ & $\begin{array}{r}\text { Grand } \\
\text { mean }\end{array}$ & $\begin{array}{c}\text { Unc } \\
(\%)\end{array}$ & $\begin{array}{r}\text { Grand } \\
\text { mean }\end{array}$ & $\begin{array}{l}\text { Unc } \\
(\%)\end{array}$ & $\begin{array}{l}\text { Grand } \\
\text { mean }\end{array}$ & $\begin{array}{l}\text { Unc } \\
(\%)\end{array}$ & $\begin{array}{l}\text { Grand } \\
\text { mean }\end{array}$ & $\begin{array}{l}\text { Unc } \\
(\%)\end{array}$ & $\begin{array}{l}\text { Grand } \\
\text { mean }\end{array}$ & $\begin{array}{l}\text { Unc } \\
(\%)\end{array}$ \\
\hline 250 & 1.48 & 1.42 & 1.4 & 0.10 & 2.4 & & & & & $12.69^{\mathrm{b}}$ & 3.9 & & & & & & & & & 1.77 & 6 & & \\
\hline 260 & 1.40 & -0.04 & 1.4 & 0.92 & 2.4 & & & & & 8.86 & 3.8 & & & & & & & & & 0.42 & 4 & & \\
\hline 270 & 1.34 & -0.44 & 1.3 & 0.96 & 2.4 & & & & & & & & & & & & & & & -1.31 & 2.5 & 4.47 & 1.2 \\
\hline 280 & 1.28 & 1.86 & 1.2 & 0.90 & 2.4 & & & & & 6.10 & 3.5 & & & & & & & -2.21 & 3.0 & -1.25 & 2 & 4.58 & 1.1 \\
\hline 290 & 1.22 & 0.95 & 1.2 & 0.00 & 2.4 & & & & & & & & & & & & & -1.46 & 2.8 & -1.29 & 1.5 & 4.53 & 1.0 \\
\hline 300 & 1.17 & 0.16 & 1.1 & 0.46 & 2.4 & & & 1.76 & 3 & 4.07 & 3.3 & -2.63 & 1 & & & -0.49 & 10 & -1.40 & 2.5 & -0.82 & 1.5 & 4.05 & 0.9 \\
\hline 310 & 1.13 & -0.03 & 1.1 & -0.62 & 2.4 & & & & & & & -2.25 & 1 & & & -1.57 & 7 & -1.52 & 2.4 & -0.39 & 1.5 & 3.68 & 0.9 \\
\hline 320 & 1.09 & -0.05 & 1.1 & -0.76 & 2.4 & -2.50 & 2.1 & & & 2.82 & 3.1 & -2.12 & 1 & & & -2.85 & 6 & -1.22 & 2.3 & -0.08 & 1.5 & 3.41 & 0.9 \\
\hline 330 & 1.06 & 0.07 & 1.1 & -0.89 & 2.4 & -0.31 & 1.9 & & & & & -0.86 & 1 & & & -3.86 & 5 & -1.37 & 2.2 & 0.55 & 1.5 & 3.60 & 0.8 \\
\hline 340 & 1.03 & 0.23 & 1.0 & -1.04 & 2.4 & 0.23 & 0.8 & & & 2.43 & 2.9 & -0.71 & 1 & & & -3.86 & 4 & -0.66 & 2.1 & 0.58 & 1.5 & 3.57 & 0.8 \\
\hline 350 & 1.01 & 0.76 & 1.0 & -0.77 & 2.4 & 0.64 & 0.4 & 0.39 & 3 & 1.94 & 2.9 & -0.17 & 0.8 & & & 0.50 & 3 & -0.82 & 2.0 & 0.52 & 1 & 3.65 & 0.7 \\
\hline 400 & 0.92 & -0.60 & 0.6 & 1.00 & 2.4 & 1.53 & 0.5 & -0.51 & 2 & 0.71 & 2.3 & 0.67 & 0.5 & 1.14 & 1.1 & 1.15 & 2 & 0.79 & 2.0 & 0.57 & 0.8 & 2.92 & 0.6 \\
\hline 450 & 0.84 & -0.12 & 0.5 & 1.79 & 2.4 & 1.26 & 0.3 & -0.18 & 2 & 0.37 & 2.2 & 0.66 & 0.4 & 0.99 & 1.1 & 2.26 & 2 & -0.13 & 1.9 & 0.36 & 0.8 & 2.52 & 0.6 \\
\hline 500 & 0.78 & -0.02 & 0.4 & 1.07 & 1.4 & 1.56 & 0.3 & -0.24 & 2 & 0.28 & 2.1 & 1.14 & 0.4 & 0.91 & 1 & 1.37 & 1.6 & -0.42 & 1.8 & -0.09 & 0.8 & 2.14 & 0.5 \\
\hline 555 & 0.73 & & & 0.75 & 1.4 & 1.76 & 0.2 & -0.35 & 2 & -0.11 & 1.9 & 0.60 & 0.2 & & & 0.34 & 1.6 & & & -0.25 & 0.8 & 1.87 & 0.5 \\
\hline 600 & 0.70 & 0.15 & 0.4 & 0.16 & 1.4 & 1.64 & 0.3 & -0.01 & 2 & 0.22 & 1.8 & 0.55 & 0.4 & 1.04 & 1 & 1.07 & 1.6 & -0.39 & 1.7 & -0.50 & 0.8 & 1.59 & 0.5 \\
\hline 654.6 & 0.68 & & & 0.40 & 1.6 & & & -0.43 & 2 & & & -0.06 & 0.4 & & & -0.07 & 1.6 & & & -0.35 & 0.8 & 1.22 & 0.4 \\
\hline 700 & 0.67 & 0.12 & 0.4 & 0.69 & 1.6 & 1.40 & 0.3 & -0.21 & 2 & -0.23 & 1.6 & 0.17 & 0.5 & 1.21 & 1 & 1.14 & 0.8 & -0.32 & 1.8 & -0.45 & 0.8 & 1.06 & 0.5 \\
\hline 800 & 0.67 & -1.58 & 0.8 & -1.24 & 1.8 & -0.25 & 0.3 & -0.74 & 2 & -0.51 & 1.6 & -0.90 & 0.8 & 1.17 & 1 & 0.83 & 0.8 & -0.31 & 1.9 & -0.10 & 0.8 & 0.38 & 0.6 \\
\hline 900 & 0.68 & -4.60 & 1.1 & -4.56 & 2.1 & -0.12 & 0.3 & -1.38 & 3 & -2.90 & 1.6 & -3.65 & 1 & 0.70 & 1.1 & -0.08 & 0.8 & -0.52 & 2.0 & 0.06 & 1 & -0.42 & 0.7 \\
\hline 1050 & 0.68 & -4.72 & 1.1 & -5.04 & 2.1 & & & -1.04 & 3 & 1.28 & 1.7 & -5.52 & 1.1 & 1.11 & 1.4 & 0.38 & 0.7 & -0.11 & 2.5 & 1.15 & 1.5 & -0.07 & 0.7 \\
\hline 1150 & 0.67 & -4.63 & 1.1 & -4.58 & 2.0 & & & -1.38 & 3 & 3.59 & 1.7 & -6.81 & 1.2 & 1.13 & 1.5 & 0.41 & 0.7 & -0.24 & 2.5 & 1.59 & 1.5 & -0.20 & 0.7 \\
\hline 1200 & 0.67 & -3.95 & 1.1 & -4.13 & 2.0 & & & -1.24 & 3 & 3.84 & 1.7 & -7.23 & 1.2 & 1.49 & 1.5 & 0.52 & 0.7 & -0.29 & 2.5 & 2.06 & 1.5 & -0.16 & 0.8 \\
\hline 1300 & 0.67 & -3.23 & 1.3 & -3.50 & 2.0 & & & -1.21 & 3 & 4.13 & 1.8 & -7.99 & 1.2 & 2.45 & 1.6 & 0.68 & 0.7 & -0.28 & 2.5 & 2.33 & 1.5 & 0.19 & 0.8 \\
\hline 1540 & 0.75 & & & -3.41 & 2.0 & & & -1.01 & 3 & 4.92 & 1.2 & -10.9 & 1.5 & & & 0.61 & 0.8 & & & 3.52 & 1.5 & -0.26 & 0.8 \\
\hline 1600 & 0.77 & -2.63 & 1.3 & -4.02 & 2.0 & & & -1.99 & 3 & 4.24 & 1.2 & -12.2 & 1.5 & & & -0.24 & 0.8 & -0.82 & 2.7 & 2.64 & 1.5 & -1.19 & 0.9 \\
\hline 1700 & 0.87 & -0.91 & 1.3 & -2.75 & 2.0 & & & -1.08 & 3 & 5.45 & 1.2 & -12.1 & 1.8 & & & & & & & 3.55 & 1.5 & -0.33 & 0.9 \\
\hline 2000 & 1.30 & -0.27 & 1.4 & -2.25 & 2.0 & & & -0.54 & 3 & 5.19 & 1.1 & -15.6 & 2 & & & & & & & 2.97 & 1.5 & -0.98 & 1.0 \\
\hline 2100 & 1.39 & -2.08 & 1.4 & -3.80 & 2.0 & & & -2.15 & 3 & 3.91 & 1.1 & -17.8 & 2 & & & & & & & 1.01 & 2.5 & -3.76 & 1.0 \\
\hline 2300 & 1.86 & -0.42 & 1.4 & -2.65 & 2.0 & & & -1.26 & 3 & 5.92 & 1.2 & -18.8 & 2.5 & & & & & & & 1.66 & 2.5 & -5.28 & 1.1 \\
\hline 2400 & 2.34 & -1.13 & 1.4 & -2.45 & 2.1 & & & -1.49 & 3 & 6.14 & 1.2 & -19.2 & 2.5 & & & & & & & -1.34 & 2.5 & -4.73 & 1.1 \\
\hline
\end{tabular}

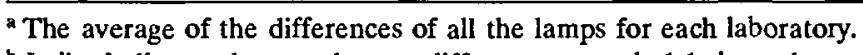

bItalics indicates the grand-mean difference exceeds 1.1 times the combined Laboratory/NIST uncertainty associated with it. 


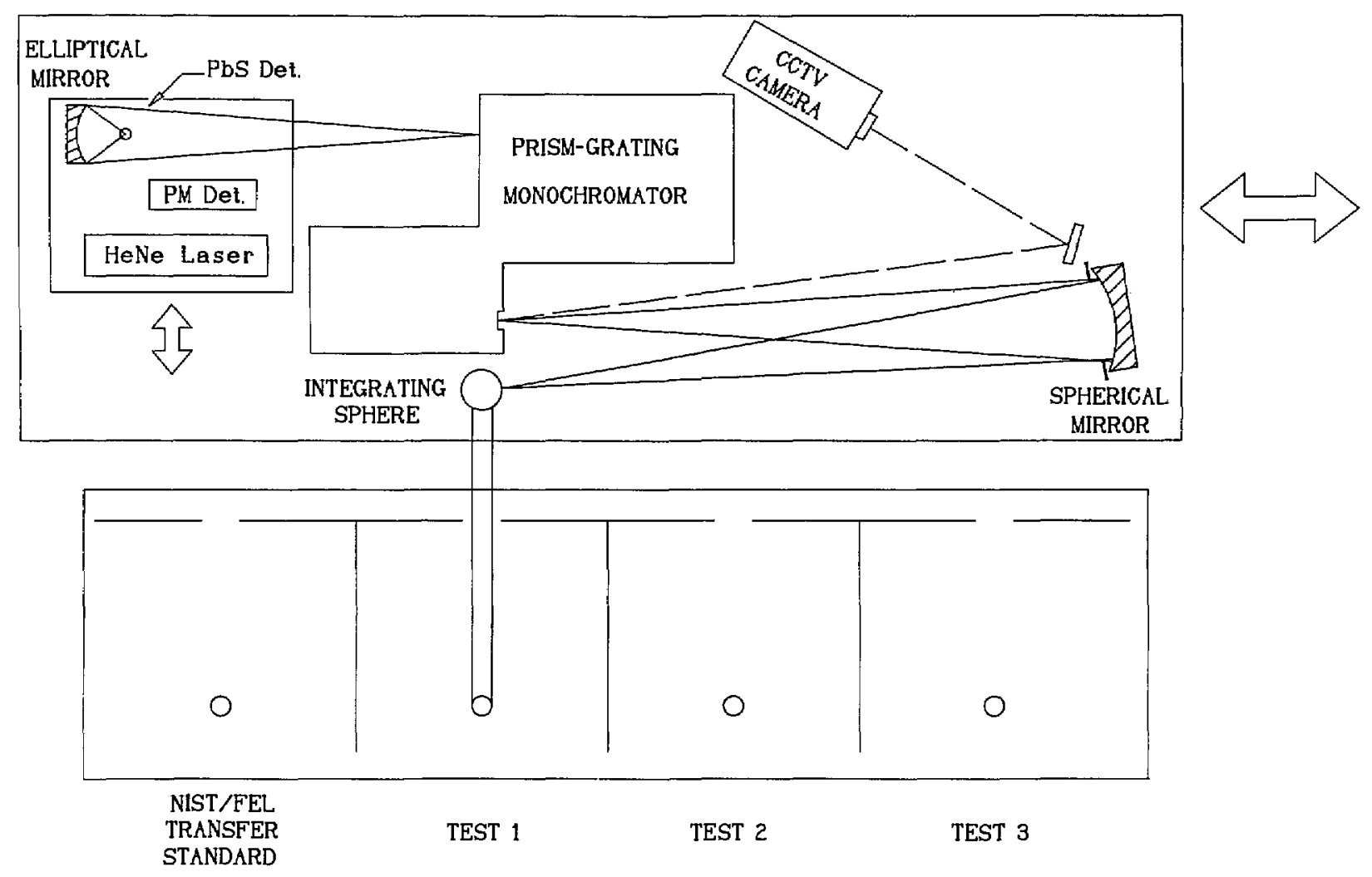

Figure 3. NIST spectral irradiance measurement equipment.

\section{Data Analysis}

After the completion of all measurements, the following data analysis was carried out by NIST staff.

(a) The percent differences from NIST defined by Eq. (1) were computed as a function of wavelength for both the round-one and round-two spectral irradiance values reported by the participating laboratories for each intercomparison lamp.

(b) The differences between these round-one and round-two differences from NIST were compared to the lamp voltage readings recorded for each lamp by the participants and by NIST. This comparison revealed a few cases in which unduly large discrepancies between the participants' round-one and round-two measurements appeared to be caused by bistable behavior of a lamp. Upon notification of these findings, five laboratories requested that the measurements of one of their lamps be excluded from the data analysis. The average absolute differences between the round-one and round-two data for the remaining lamps were small (ranging from $1.4 \%$ at $250 \mathrm{~nm}$ through $0.5 \%$ at $600 \mathrm{~nm}$ to $1 \%$ at $2400 \mathrm{~nm}$ ) and were not included in the error analysis.

(c) The averages of the round-one and round-two percent differences from NIST were computed for each lamp, and the average of these differences of all the lamps measured by each participating laboratory was computed to serve as the "grand mean" for each laboratory. A sample of the data analysis for one laboratory is shown in Appendix B.

(d) As an independent measure for judging the statistical significance of the grand-mean differences, the quadrature combination of the one standard deviation uncertainties quoted by NIST and each laboratory was computed.

Appendix $\mathrm{C}$ contains a plot for each laboratory showing its grand mean percent difference from NIST and the combined Lab/NIST one standard deviation uncertainty. 


\section{Results and Discussion}

Table 2 shows the grand-mean percent differences from NIST and the one standard deviation uncertainties of each laboratory's measurements. A plot of the grand-mean differences versus wavelength is shown in Fig. 4. Differences greater than $\pm 6 \%$ are not shown on this plot, but can be found in Table 2.

As a visual aid in relating the results obtained for each laboratory to their estimated uncertainties, every grand-mean difference that exceeds 1.1 times $^{3}$ the combined laboratory/NIST uncertainty associated with it (as defined in Sec. 6(d), above) has been highlighted in Table 2. The number of measurements thus identified is:

$$
\begin{aligned}
& \text { ultraviolet region (250 to } 350 \mathrm{~nm} \text { ) } \\
& 16 \text { of } 75 \text { measurements }(21 \%) \\
& \text { visible region ( } 400 \text { to } 800 \mathrm{~nm}) \\
& 15 \text { of } 80 \text { measurements }(19 \%) \\
& \text { infrared region (900 to } 2400 \mathrm{~nm}) \\
& 48 \text { of } 102 \text { measurements }(47 \%)
\end{aligned}
$$

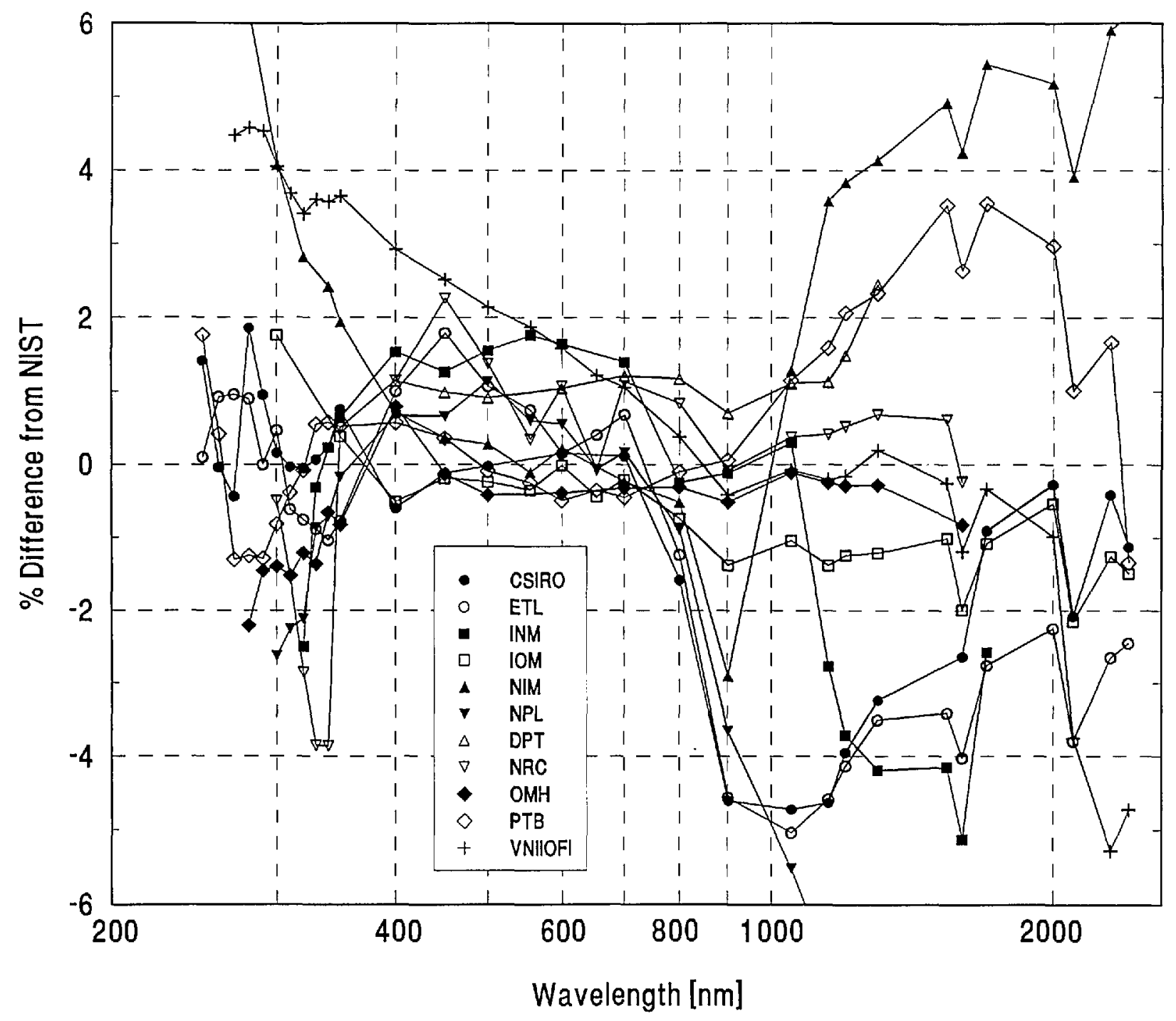

Figure 4. Grand-mean percent differences from NIST of all participants' spectral-irradiance measurements.

\footnotetext{
${ }^{3}$ The 1.1 factor was applied to avoid computer rejection of data that fell just barely outside the one standard deviation level.
} 
This result should, however, be viewed with caution because it depends on the uncertainty estimates provided by the participating laboratories and because these estimates vary considerably among laboratories. We noted that the participants' uncertainty estimates for many of the highlighted measurements in Table 2 are quite low, and that there are several instances in which grandmean differences of similar magnitude but larger estimated uncertainties survived the "highlighting" criterion used in Table 2 . In this context it may be of interest to compare the uncertainties estimated by each laboratory to the average of the estimates provided by all laboratories. This average, excluding the uncertainty of measurements which deviate significantly from the world mean (NIM in the 250 to $280 \mathrm{~nm}$ region and NPL in the 900 to $2400 \mathrm{~nm}$ region) is shown in Table 3 as a function of wavelength, and hence it may be seen that the participants' uncertainty estimates are lower than average in the case of 54 of the 79 highlighted measurements in Table 2. This appears to indicate that the uncertainties assigned by some national laboratories may be too small, at least at the one standard deviation level.

As a measure of the world-wide consistency of spectral-irradiance measurements we calculated both the average and the standard deviation of the grand-mean differences from NIST, again excluding the measurements which deviate significantly from the world mean (NIM in the 250 to $280 \mathrm{~nm}$ region and NPL in the 900 to $2400 \mathrm{~nm}$ region). The results of this calculation are also given in Table 3 and show that the world-average difference from NIST is within the world-average uncertainty estimate for every intercomparison wavelength and exceeds its own standard deviation at one wavelength only $(250 \mathrm{~nm})$. However, the standard deviation of the world-average difference from NIST is within the world-average uncertainty estimate only in the visible region, but exceeds it for several ultraviolet wavelengths and for every infrared wavelength from $900 \mathrm{~nm}$ upwards. Using the standard deviation of the world average as a measure, we estimate the consistency of the national scales and the intercomparison measurements to be on the order of $1 \%$ in the visible region ( 400 to $800 \mathrm{~nm}$ ) and on the order of 2 to $4 \%$ in the ultraviolet and infrared regions. The overall spread of results is, of course, greater and may be inferred from Table 2.
Table 3. World averages of one standard deviation uncertainty estimates, percent differences from NIST, and comparison with 1975 ETL intercomparison

\begin{tabular}{|c|c|c|c|c|c|}
\hline \multirow[b]{2}{*}{$\begin{array}{l}\text { WL } \\
(\mathrm{nm})\end{array}$} & \multirow{2}{*}{$\begin{array}{l}\text { World average } \\
\text { of the estima- } \\
\text { ted uncertain- } \\
\text { ties of all } \\
\text { laboratories } \\
\text { Av unc } \\
(\%)\end{array}$} & \multicolumn{2}{|c|}{$\begin{array}{l}\text { World average and } \\
\text { standard devia- } \\
\text { tion of grand- } \\
\text { mean differences } \\
\text { from NIST }\end{array}$} & \multicolumn{2}{|c|}{$\begin{array}{l}\text { World average and } \\
\text { standard devia- } \\
\text { tion of differences } \\
\text { from world aver- } \\
\text { age of } 1975 \mathrm{ETL} \\
\text { intercomparison }\end{array}$} \\
\hline & & $\begin{array}{l}A v^{b} \\
(\%)\end{array}$ & $\begin{array}{l}\text { Std dev } \\
(\%)\end{array}$ & $\begin{array}{l}\mathrm{Av} \\
(\%)\end{array}$ & $\begin{array}{c}\text { Std dev } \\
(\%)\end{array}$ \\
\hline 250 & 2.82 & 1.10 & 0.88 & & \\
\hline 260 & 2.30 & 0.43 & 0.48 & & \\
\hline 270 & 1.75 & 0.92 & 2.54 & & \\
\hline 280 & 1.83 & 0.78 & 2.68 & & \\
\hline 290 & 1.69 & 0.55 & 2.44 & & \\
\hline 300 & 2.69 & 0.57 & 2.32 & 0.00 & 1.33 \\
\hline 310 & 2.18 & -0.38 & 1.95 & & \\
\hline 320 & 2.15 & -0.37 & 2.22 & & \\
\hline 330 & 1.88 & -0.38 & 2.09 & & \\
\hline 340 & 1.76 & 0.09 & 2.12 & & \\
\hline 350 & 1.66 & 0.66 & 1.32 & 0.00 & 1.14 \\
\hline 400 & 1.31 & 0.85 & 0.95 & 0.00 & 1.42 \\
\hline 450 & 1.26 & 0.89 & 0.96 & & \\
\hline 500 & 1.09 & 0.70 & 0.84 & 0.00 & 0.77 \\
\hline 555 & 1.04 & 0.58 & 0.86 & & \\
\hline 600 & 1.05 & 0.50 & 0.74 & 0.00 & 0.54 \\
\hline 654.6 & 1.07 & 0.12 & 0.61 & & \\
\hline 700 & 1.00 & 0.42 & 0.70 & 0.00 & 0.54 \\
\hline 800 & 1.09 & -0.29 & 0.84 & 0.00 & 2.42 \\
\hline 900 & 1.31 & -1.38 & 1.95 & & \\
\hline 1050 & 1.54 & -0.78 & 2.44 & & \\
\hline 1150 & 1.54 & -0.48 & 2.72 & & \\
\hline 1200 & 1.55 & -0.21 & 2.63 & & \\
\hline 1300 & 1.59 & 0.17 & 2.57 & & \\
\hline 1540 & 1.44 & 0.73 & 3.05 & & \\
\hline 1600 & 1.57 & -0.50 & 2.73 & & \\
\hline 1700 & 1.54 & 0.66 & 3.14 & & \\
\hline 2000 & 1.61 & 0.69 & 2.80 & & \\
\hline 2100 & 1.77 & -1.14 & 3.03 & & \\
\hline 2300 & 1.87 & -0.34 & 3.84 & & \\
\hline 2400 & 1.95 & -0.83 & 3.66 & & \\
\hline
\end{tabular}

Does not include the uncertainties of NIM from 250 to $280 \mathrm{~nm}$ or of NPL from $900-2400 \mathrm{~nm}$.

${ }^{b}$ Does not include the grand-mean differences of NIM from 250 to $280 \mathrm{~nm}$ or of NPL from $900-2400 \mathrm{~nm}$.

Figure 4 and Table 3 show that the spectralirradiance measurements performed by NIST assigned slightly lower values than the world average throughout the visible region and at several ultraviolet wavelengths, and tend to be slightly higher in the infrared region. In particular, Fig. 4 shows that dips on the order of $1 \%$ appear in most participants' differences from NIST at 1600 and $2100 \mathrm{~nm}$. These dips may be caused by variations in the NIST scale which are within NIST's uncertainty estimates. 
We looked for systematic differences between spectral-irradiance scales based on different physical principles. As noted in Sec. 4(a), the NIST scale and a large number of the others are based on blackbodies. As may be seen in Fig. 5, the three scales based on absolute detector radiometry (IOM, DPT, and NRC above $700 \mathrm{~nm}$ ) show no significant differences from NIST or from the world average and were therefore judged to be consistent with blackbody scales. However, the three detector based scales appear to have better agreement in the ir region than the non-detector based scales.
The only other measurements not based on blackbody physics (the synchrotron-based NPL measurements below $370 \mathrm{~nm}$ ) appear to have yielded somewhat lower values than NIST near $300 \mathrm{~nm}$.

For comparison purposes, we have included on the right-hand side of Table 3 the standard deviations of the world averages obtained in the 1975 spectral-irradiance intercomparison conducted by ETL [3]. ${ }^{4}$ This shows that the results of the present intercomparison are not too different, except that more laboratories participated and that a greater spectral region was covered.

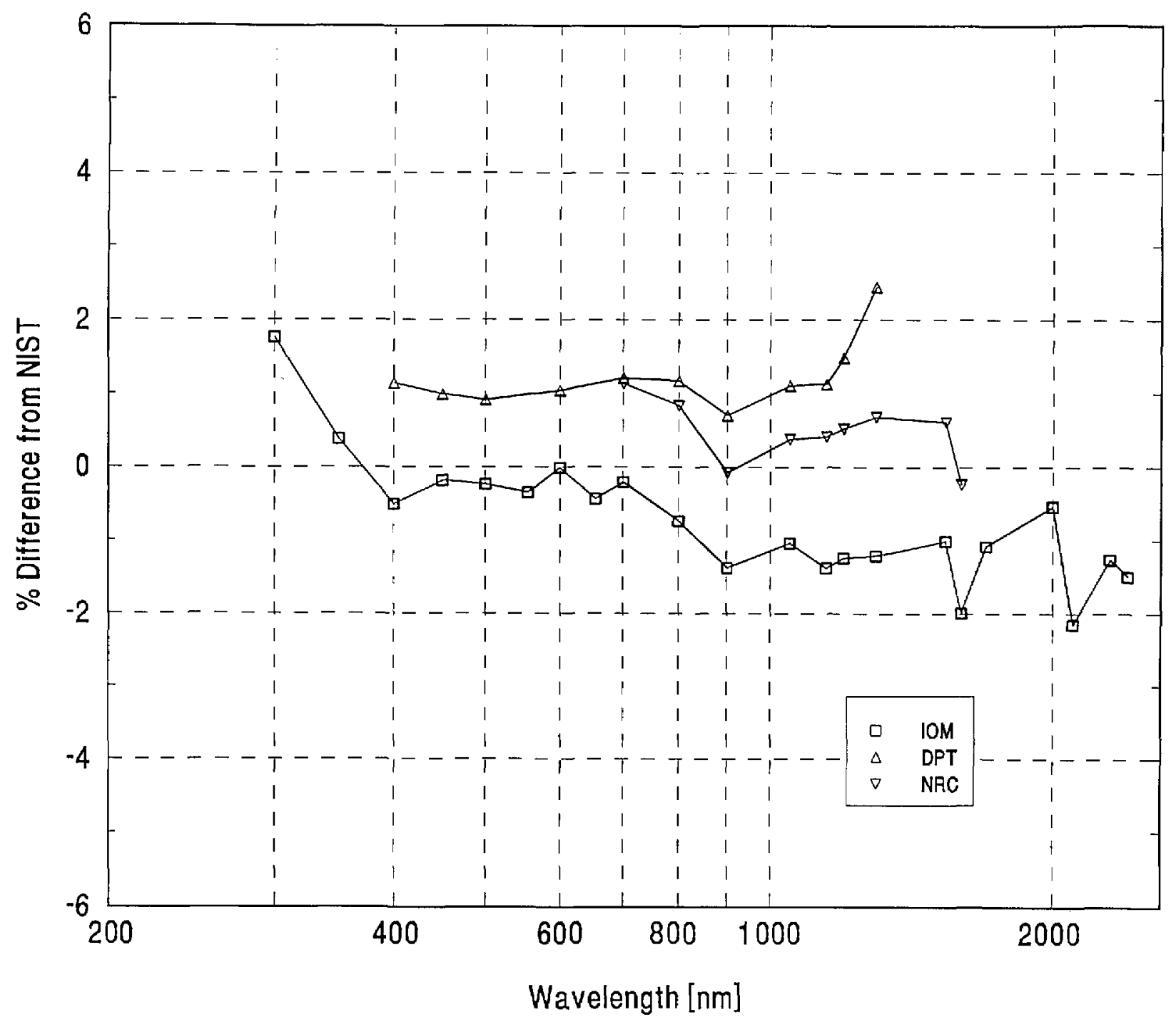

Figure 5. Grand-mean percent differences from NIST of participants with detector-based scales.

\footnotetext{
${ }^{4}$ The world average and the standard deviation of differcnces from world average were recalculated without using the ASMW data.
} 


\section{Appendix A. Descriptions of the Scale Derivations of the Participating Laboratories}

Each laboratory was asked to give a one page or less description of the derivation of its spectral irradiance scale. These descriptions that were submitted are given here.

\subsection{Derivation of the NIST (USA) Spectral Irradiance Scale}

\section{Realize Spectral Radiance Scale}

1. A beam conjoiner is used to measure the responsivity (linearity) of the photomultiplier amplifier system of our spectroradiometer.

2. Lamp V25 (high stability Quinn-Lee type vacuum lamp) is calibrated against a gold point blackbody at $654.6 \mathrm{~nm}$.

3. Lamp C706 (high stability GEC type vacuum lamp) is calibrated against V25 at $654.6 \mathrm{~nm}-$ C706 has approximately eight times the output of V25 at $654.6 \mathrm{~nm}$.

4. Lamp C706 is used to determine the temperature of a variable temperature blackbody which operates over a range of 1050 to $2700 \mathrm{~K}$.

5. The spectral radiance of a test source is compared to the spectral radiance of the blackbody at some test wavelength and Placnk's equation is used to determine the spectral radiance of the test source.

Realize Spectral Irradiance Scale on Primary Working Standards

1. Steps 4 and 5 from above are carried out to perform a spectral radiance calibration on the output of a small integrating sphere source (5.1 $\mathrm{cm}$ diameter sphere with a $1.8 \mathrm{~cm}$ diameter exit aperture) from 250 to $2400 \mathrm{~nm}$.

2. Our spectroradiometer is then put in its spectral irradiance mode where it has a small averaging sphere $(3.8 \mathrm{~cm}$ diameter sphere with a $1.2 \mathrm{~cm}$ entrance aperture) as the receiving optic.

3. At each wavelength the output of the primary working standards are compared to the output of the integrating sphere source.

4. The aperture sizes of the integrating sphere and the averaging sphere are accurately known and we accurately measure the distance between the two apertures. With this information we can calculate the spectral irradiance of the sphere source at the aperture of the averaging sphere.

5. After determining the ratio of a primary working standard output to the sphere source output, we can calculate the spectral irradiance of the primary working standard. This is done for each primary working standard.

\section{Spectral Irradiance Scale Transfer}

1. Four primary working standards are used to calibrate a group of 12 test lamps.

2. Each test lamp is measured four times-once in each of four test positions and against each of the four primary working standards.

\subsection{Derivation of the CSIRO (Australia) Spectral Irradiance Scale}

\section{Relative Spectral Radiance Scale}

The temperature of a tungsten-tube type cavity radiator (Ostam lamp type Wi80) at about $2700 \mathrm{~K}$ was measured using broad-band filters, a non-selective thermal detector and application of Planck's law. Using Planck's law the relative spectral radiances were calculated for the limited wavelength range $350-800 \mathrm{~nm}$.

\section{Relative Spectral Irradiance Scale}

1. A matched-pair of colour-corrected lenses, in conjugate positions with a magnification or demagnification of a factor of ten, was used to image the selected region of the cavity lamp or the whole filament of an irradiance standard lamp (Wotan type Wi41G) in turn, within the entrance aperture of an integrating sphere attached to a spectroradiometer. The transfer was also limited to the wavelength range 350 $800 \mathrm{~nm}$.

2. The scale of relative spectral irradiance was transferred from the Wotan lamp standards to working standard tungsten-halogen lamps (Ushio Electric $100 \mathrm{~V} 500 \mathrm{~W}$ ) by irradiating in turn a barium sulphate plate which was imaged onto the spectroradiometer entrance slit.

\section{Spectral Irradiance Scale-SI Units}

The illuminance of each working standard tungsten-halogen lamp was measured at the defined position using an electrical substitution absolute radiometer fitted with a $V(\lambda)$ correction filter with 
accurately-measured spectral transmittances. The conversion factor $683 \mathrm{~lm} / \mathrm{W}$ was used for the wavelength $555 \mathrm{~nm}$, and correction was made for departure of the detector from $V(\lambda)$. From the illuminance and the known relative spectral power distribution the spectral irradiances were calculated for the wavelength range $350-800 \mathrm{~nm}$.

\section{Spectral Irradiance Scale - uv and ir Spectral Regions}

The CSIRO Spectral Irradiance Scale for the wavelength ranges $250-350 \mathrm{~nm}$ and $800-2400 \mathrm{~nm}$ was adopted in 1975 from the ETL (Japan) scale of 1973. We also observed at the time good agreement with the NPL (UK) scale over the range 290$760 \mathrm{~nm}$. We have no knowledge of the dependence of this borrowed scale on IPTS scales.

As the CSIRO scale is not independently based for the wavelength ranges $250-340 \mathrm{~nm}$ and 850 $2400 \mathrm{~nm}$, we suggest that only values from the CSIRO scale for the wavelength range $350-800 \mathrm{~nm}$ be used for the calculation of international mean values.

\subsection{Derivation of the ETL (Japan) Spectral Irradiance Scale}

\section{Realization of Spectral Radiance Scale on Shelf Stan-} dards $-A$

1. Three blackbodies, a gold-point, a nickel-tube, and a graphite-tube were constructed.

2. The temperature of the graphite-tube blackbody, which operated over a range of 2200 to $2500 \mathrm{~K}$, was determined from the measured ratio of its spectral radiance to that of the goldpoint black-body at 550,600 , and $650 \mathrm{~nm}$.

3. The temperature of the nickel-tube blackbody, which operated within a range of 1520 to 1570 $\mathrm{K}$, was determined by optical pyrometer calibrated against NRLM standard of radiance temperature.

4. Spectral radiances of six tungsten strip lamps (GE 30A/T24) were calibrated against those of the blackbodies from 250 to $2500 \mathrm{~nm}$; all of the three blackbodies were referenced for the wavelengths longer than $1200 \mathrm{~nm}$, whereas only the graphite-tube one was referenced for the shorter wavelengths.

Realization of Spectral Irradiance Scale on Shelf Standards $-B$

1. Spectral distributions of radiation from three quartz-bromine lamps (Ushio JPD-100-500-
CS) were measured by comparing spectral irradiances alternately produced on a white diffusing surface by each of the lamps and by one of the strip lamps (our shelf standards of spectral radiance); two strip lamps were used.

2. The absolute value of spectral irradiance of each of the quartz-bromine lamps was measured at 580 and $600 \mathrm{~nm}$ by comparing spectral radiance of a smoked $\mathrm{MgO}$ surface irradiated by the lamp with that of one of the strip lamps; two strip lamps were used; the spectral radiance factor of the smoked $\mathrm{MgO}$ surface was determined from measured reflectance.

3. The absolute value of integrated irradiance from each of the quartz-bromine lamps was measured by a radiometer combined with a band-pass (300-2750 nm) filter; the radiometer was calibrated in terms of the ETL absolute radiometric scale. The absolute value of spectral irradiance was calculated from the measured integrated irradiance, spectral distribution determined in step 1 , and the spectral transmittance of the filter.

4. The absolute value of spectral irradiance at 580 and $600 \mathrm{~nm}$ was determined by averaging the results of steps 2 and 3.

5. The spectral irradiance at the whole wavelength range of 250 to $2500 \mathrm{~nm}$ was determined by combining the results of steps 1 and 4 .

\section{Amendment of Spectral Iradiance Scale in the} Shorter Wavelengths

1. Spectral distribution of the shelf standards was compared with that of synchrotron radiation over the wavelength range of 250 to $600 \mathrm{~nm}$.

2. The spectral irradiance scale determined in step 5 of part B was amended in order that the spectral distribution would conform with the result of step 1 for the wavelengths shorter than $500 \mathrm{~nm}$.

\subsection{Derivation of the INM (France) Spectral Irradiance Scale}

\section{Realize Spectral Radiance Scale}

1. A separate apparatus is used to measure the linearity of photomultiplier and photodiode of our spectroradiometer.

2. Two lamps $337 \mathrm{C}$ and $340 \mathrm{C}$ (20-24G GEC type gas filled lamps) are calibrated against radiance temperature standards of our pyrometry laboratory (high stability GEC type vacuum 
lamp calibrated against gold point black body).

3. These lamps are used to determine the temperature of a variable temperature black body which operates over a range of 1500 to $1950 \mathrm{~K}$.

4. The spectral radiance of test sources (339C and $367 \mathrm{C}$ ) is compared to the spectral radiance of the black body and Planck's equation is used to determine the spectral radiance of the test source.

Realize Spectral Irradiance Scale on Intercomparison Lamps

1. At each wavelength our spectroradiometer is switched from radiance mode for response to radiance standard, to irradiance mode for response to irradiance source.

2. Relative irradiance values are calculated from ratio of these two responses. Irradiance is fixed to 1 for $550 \mathrm{~nm}$.

3. Luminous intensity of intercomparison lamps is compared to luminous intensity standards. Luminous intensity scale is based on use of electrical substitution pyroelectric radiometer.

4. From relative irradiance values and luminous intensity we can calculate irradiance values.

5. Each intercomparison lamp is compared to two radiance standards lamps and four luminous intensity lamps.

\subsection{Derivation of the IOM (Spain) Spectral Irradiance Scale}

The spectral irradiance scale of the Institute of Optics is based on an electrically calibrated pyroelectric radiometer and maintained in FEL type lamps.

The derivation process is as follows:

a) Measurement of the spectral transmittance of interference filters.

b) Measurement of the irradiance produced by the lamps, filtered by the interference filters, at $50 \mathrm{~cm}$ away from the lamp by using the ECPR.

c) Corrections to the measurements in order to take into account filters thickness and bandwidth.

d) Interpolation of the lamp spectral irradiance values from the measurements points. The De Voss' approximation is used.

\subsection{Derivation of the NIM (People's Republic of China) Spectral Irradiance Scale}

Primary standard is a high temperature (about $2800 \mathrm{~K}$, variable) black body radiator. A precise circular diaphragm is placed at the exit port of the radiator. The spectral irradiance was measured at the place which is departure from the precise diaphragm in a fixed distance $(500 \mathrm{~mm})$.

The secondary standard is a group of 10 tungstenhalogen lamps (1000 W).

The comparator is a high accuracy wide wavelength range spectral radiometer which was developed at NIM.

\subsection{Derivation of the NPL (UK) Spectral Irradi- ance Scale}

The NPL spectral irradiance scale is based, over the wavelength range $350-800 \mathrm{~nm}$, on comparisons with a black body cavity radiator. The spectral radiance of a group of tungsten ribbon filament lamps was measured by a direct comparison with the radiance of the cavity radiator and a radiance/irradiance transfer was then carried out to establish a relative spectral irradiance scale. The irradiance scale is held by a group of secondary standard coiled tungsten filament lamps.

In order to maintain internal consistency between the various optical radiation scales maintained at NPL, the absolute level of the scale has been assigned by relating it to the national scale of luminous intensity which was established radiometrically and is based on the NPL cryogenic radiometer.

At wavelengths from $200-370 \mathrm{~nm}$, the relative spectral power scale has been established based on synchrotron radiation, which was used to calibrate a group of low pressure deuterium lamps. Again, the first stage of the calibration involved the establishment of a scale of spectral radiance which was then used to provide a scale of relative spectral irradiance on the same deuterium lamps. The absolute level has been assigned by comparison at 350 $\mathrm{nm}$ with the black body based scale described above.

The accuracy of the scale has subsequently been checked and confirmed at a number of points in over the wavelength range $400-800 \mathrm{~nm}$ by the use of a series of filter radiometers, each consisting of a specially constructed narrow band interference 
filter combined with a silicon call. The spectral responsivity curve for each of the radiometers was characterized using a tuneable dye laser and the absolute responsivity obtained by a direct comparison with the NPL spectral responsivity scale based on the cryogenic radiometer.

When the intercomparison started, work was in progress to extend the wavelength range covered by the NPL spectral irradiance scale into the infrared, but this work had not been completed. Rather than opt out completely in the infrared, NPL decided to measure the lamps and submit results based on a provisional calculation using published data for the emissivity of tungsten. It was hoped that these results could later be corrected to incorporate the new scale before the end of the intercomparison. Unfortunately, however, further unforseen problems were encountered which prevented NPL from completing the work on time.

\subsection{Derivation of the DPT (South Africa) Spectral Irradiance Scale}

Our spectral irradiance measurements were made over the wavelength region $400-1300 \mathrm{~nm}$.

The method was based on an absolute radiometer and a series of interference filters which were used to determine the spectral irradiances of quartz halogen incandescent lamps at a number of discrete wavelengths. Values at intermediate wavelengths were obtained by interpolation.

The spectral transmittances of 11 interference filters together with a Schott K50 glass filter were measured with a Jobin Yvon Model HRD1 double monochromator, using a configuration which closely reproduces the actual geometry used in the spectral irradiance measurements. These measurements were verified on a Hitachi Model U-3400 spectrophotometer.

A pyroelectric detector, previously calibrated against an absolute radiometer, was then used in conjunction with the filter combinations mentioned above to measure the actual spectral irradiances around the different effective wavelengths.

Irradiance values at intermediate wavelengths were determined by a least square fitting to a polynomial function.

\subsection{Derivation of the NRC (Canada) Spectral Irradiance Scale}

\section{UV-Visible $(300-800 \mathrm{~nm})$}

This scale is maintained on eight $500 \mathrm{~W}$ quartzhalogen lamps similar to the lamps used in the last intercomparison [Suzuki and Ooba, Metrologia 12, 123 ( 1976 )]. The working distance is $50 \mathrm{~cm}$. The lamps were calibrated originally by means of an NBS spectral irradiance standard. After the above intercomparison, the spectral irradiance values of the eight lamps were adjusted to be equal to the world mean of that intercomparison. These adjusted values have been used since, without applying ageing corrections.

\section{Near-Infrared $(700-1600 \mathrm{~nm})$}

This is a new scale, realized at NRC in 1989-90. Electrical substitution absolute radiometers were used in conjunction with interference filters to measure directly the spectral irradiance of FEL and NPL/GEC tungsten-halogen lamps from 700 $\mathrm{nm}$ to $1600 \mathrm{~nm}$, at $100 \mathrm{~nm}$ intervals. The working distance is $100 \mathrm{~cm}$. Interpolation techniques are used to obtain values at intermediate wavelengths.

\section{For This Intercomparison}

The old scale ( $300-800 \mathrm{~nm}$ ) was used to calibrate the lamps from $300 \mathrm{~nm}$ up to and including 654.6 $\mathrm{nm}$. The lamps used in the intercomparison are some of the lamps used to realize the new scale in the near ir. The new scale spectral irradiance values were used from 700 to $1600 \mathrm{~nm}$. A correction factor was applied to transfer from a working distance of $100 \mathrm{~cm}$ to a working distance of $50 \mathrm{~cm}$. This correction factor was determined for each lamp by measuring the variation of irradiance with distance.

\subsection{Derivation of the OMH (Hungary) Spectral Irradiance Scale}

\section{Realization of Spectral Irradiance Scale}

1. Today our spectral irradiance scale is based on two FEL $8 \mathrm{~A} / 1000 \mathrm{~W}$ irradiance standard lamps calibrated by NIST.

2. We have developed a wide band filter-radiometer with eight bandfilters made of absorbing glasses and a precision aperture. The spectral response calibration of the device is based on our absolute spectral responsivity scale and high accuracy spectral transmittance measurements.

3. The integrated spectral responses were measured for the investigated irradiance standard lamps by means of the eight bandfilters. 
4. The spectral irradiance of the standard lamps in the spectral range of $330-800 \mathrm{~nm}$ is being determined from the eight measurement results with the help of a least squares fitting deconvolution program. This program needs further development.

5. The measurement results sent by $\mathrm{OMH}$ for the intercomparison are based on our calibrated lamps. We plan to send our bandfilter-radiometer based results too by May.

\section{Spectral Irradiance Scale Transfer}

1. Our spectral irradiance transfer spectroradiometer consists of a small averaging sphere $(10 \mathrm{~cm}$ diameter sphere with a $2.6 \mathrm{~cm}$ entrance aperture) as a receiving optic, a double grating monochromator, imaging optics, detectors (Si photodiode, $\mathrm{PbS}$ photoresistor, photomultiplier) and an ac current to voltage converter lock in system.

2. At each wavelength the output of our spectral irradiance standards were measured with our spectroradiometer.

3. At each wavelength the output of the test lamps were measured with our spectroradiometer.

4. Then the standard lamps were remeasured at each wavelength in order to take in consideration the long term instability of the measuring system.

5. After determining the ratio of the standard lamps output to the test lamps output, we can calculate the spectral irradiance of the test lamps.

6. Each lamp was measured four times.

\subsection{Derivation of the PTB (Germany) Spectral Irradiance Scale}

The spectral irradiance scale is based on a Planckian radiator with accurately known temperature and area realized by a variable-temperature blackbody with a large-area, water-cooled measuring aperture. The blackbody temperature of approximately $2800 \mathrm{~K}$ is measured with a linear pyrometer calibrated at PTB. The spectral irradiance at an accurately measured distance of $1 \mathrm{~m}$ to the aperture is derived from the spectral radiance of the Planckian radiator at the set temperature and the accurately measured area of the aperture with a diameter of approximately $10 \mathrm{~mm}$. The transfer of the spectral irradiance scale of the blackbody to that of the standard lamp(s) is performed by comparing the radiance of a plane reflection standard (BaSO4) defining the measuring plane which is perpendicularly irradiated by both sources, blackbody and standard lamp(s), in succession. Each of our three CCPR test lamps is calibrated three times per round at a distance of $70 \mathrm{~cm}$ to the measuring plane against a group of four standard lamps where all lamps are placed on the same optical axis. In addition, an uncalibrated highly stabilized monitor or comparison lamp is always used to correct for residual instabilities of the electrical and optical setup during the measurement. The factors to correct the spectral irradiance of the test lamps for the required distance of $50 \mathrm{~cm}$ are measured separately, where it is verified that the factors are independent of wavelength.

An improved spectroradiometer is just being put into operation.

\subsection{Derivation of the VNIIOFI (USSR) Spectral Irradiance Scale}

\section{Lamp Calibration Method}

Calibrations of the lamps have been carried out against the Radiometric Standard of the USSR. Method of measurements is based on the use of a graphite blackbody model (BBM) of BBM-2500 type. Operating temperatures of the $\mathrm{BBM}$ can vary within the range of 1700 to $2600 \mathrm{~K}$. The BBM temperature was maintained with the accuracy of $\pm 0.3 \mathrm{~K}$. BBM-2500 was installed inside a vacuum chamber provided with a quartz output window which transmission spectrum was measured by the standard spectrophotometer.

BBM was mounted on a special support together with a test lamp, a set of screens, a rotatable integrating sphere and a mirror condenser used to focus the integrating sphere exit port onto the spectrometer entrance slit. The integrating sphere is made of "Halon" type material and has the following dimensions: the sphere diameter $-40 \mathrm{~mm}$, the entrance and exit port diameters $-11 \mathrm{~mm}$ and $5 \mathrm{~mm}$, respectively, with the angle between the ports being $90^{\circ}$. The sphere is fitted with a rotary mechanism to allow for turning the entrance port to face either the BBM or the test lamp. The condenser is built of two off-axis parabolic mirrors with a focus distance of $822 \mathrm{~mm}$. The double monochromator HRD-1 ("Jobin Yvon," France) in combination with a set of photomultipliers and photoresistance cells was used as a spectrometer. 
Calibration of the test lamps for spectral irradiance consisted of two stages.

1. During the first stage, the relative spectral irradiance distribution of the lamps was measured. Incidentally, the distance from the entrance port of the integrating sphere to the lamp was set at $1200 \mathrm{~mm}$, while that to the BBM aperture diaphragm was $300 \mathrm{~mm}$. The BBM aperture diaphragm was placed inside a vacuum chamber and had a diameter of $8 \mathrm{~mm}$. this provided for ensuring an adequate level of signal from BBM throughout the entire spectrum range. Independence of the relative spectral distribution of irradiance against a distance to a lamp and the BBM aperture diaphragm was under control.

2. During the second stage, the lamp and the BBM aperture diaphragm were positioned at a distance of $500 \pm 0.1 \mathrm{~mm}$ from the entrance port of the integrating sphere (besides, BBM aperture diaphragm was located outside the vacuum chamber and its diameter was $3 \pm 0.001$ $\mathrm{mm}$ ) and the absolute spectrum of the lamp was found at several wavelengths in the visible region of the spectrum.

\section{Appendix B. Plots Showing the Data Analysis for One of the Laboratories}

Section 6 of the main paper describes the data analysis. A sample of the data analysis is given here. The data analysis for PTB is shown graphically in Figs. 6 to 10 .

\section{Appendix C. Plots of the Grand- Mean Percent Difference from NIST and the Combined Lab/NIST Uncer- tainty}

Figures 11 to 21 show the grand-mean percent difference from NIST and the combined Lab/NIST uncertainty for each laboratory. The combined $\mathrm{Lab} / \mathrm{NIST}$ uncertainty is the quadrature sum of the one standard deviation uncertainty reported by the laboratory and the one standard deviation uncertainty reported by NIST (given in Table 2).

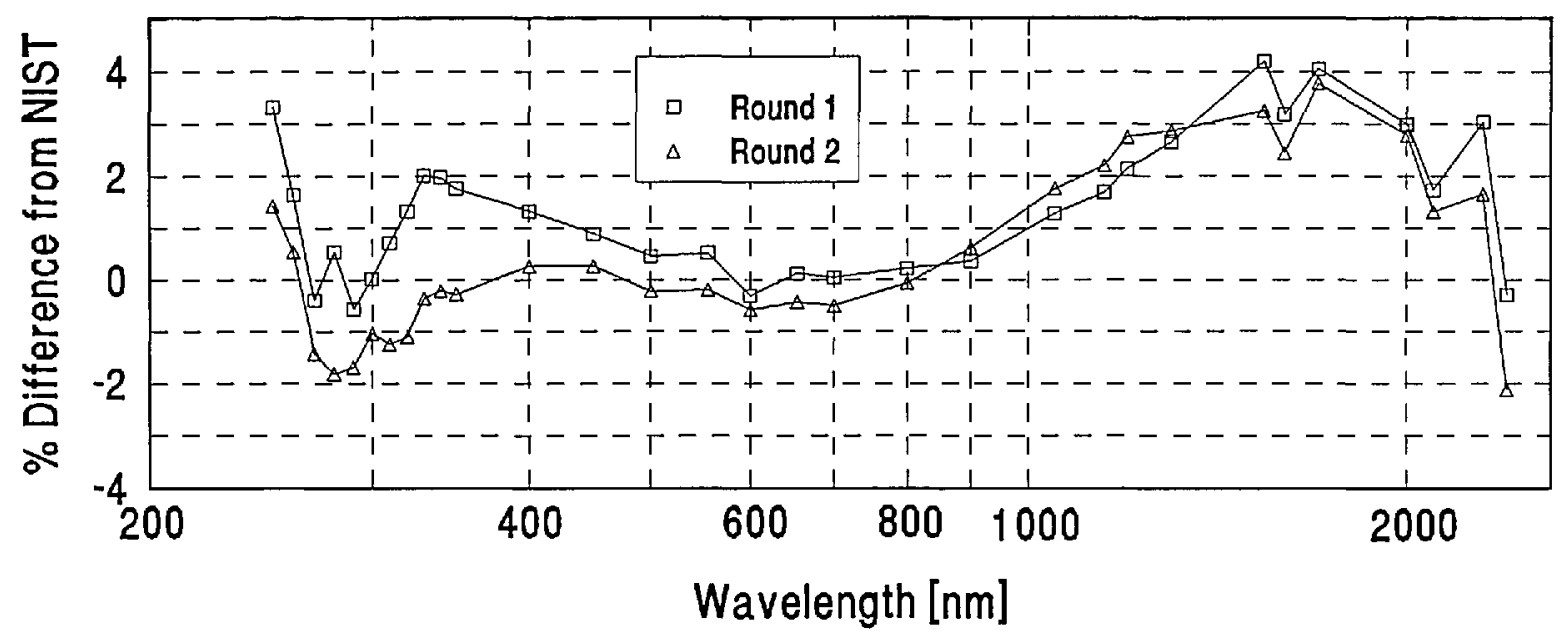

Figure 6. PTB Lamp E9 percent difference from NIST. 


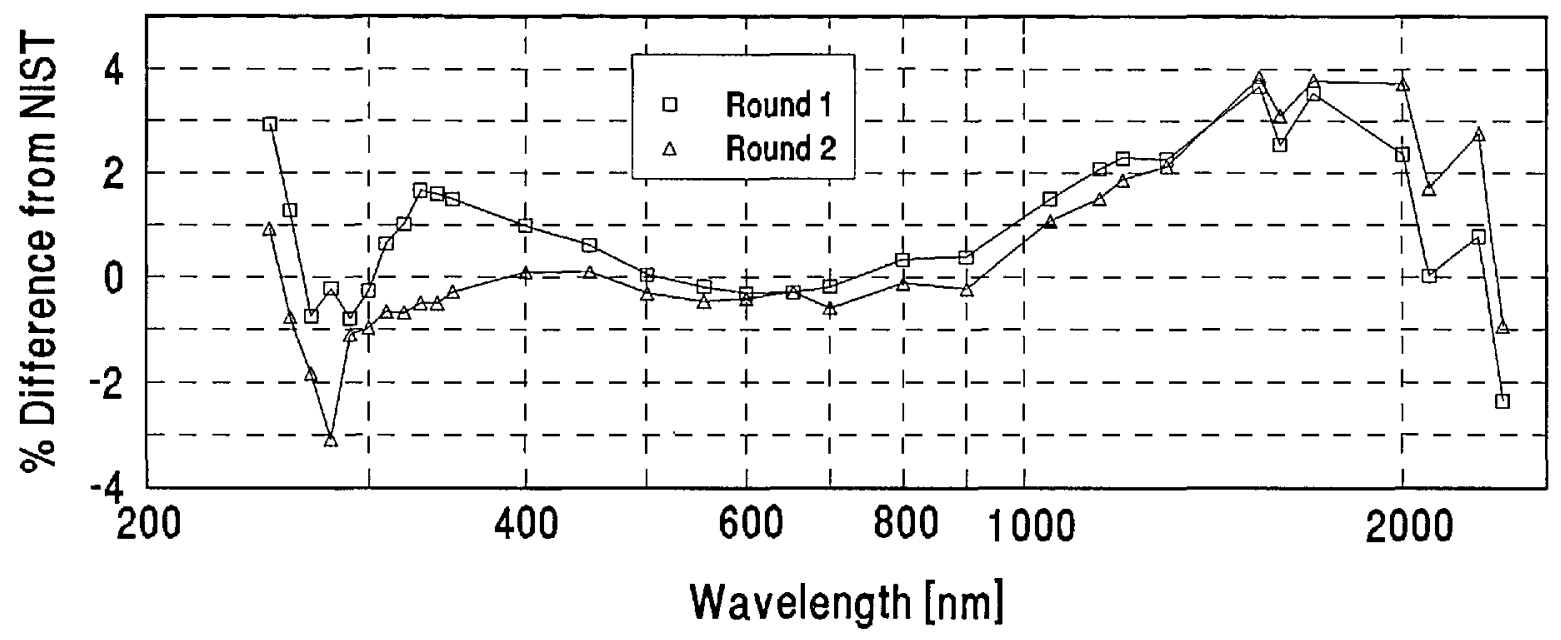

Figure 7. PTB lamp E10 percent difference from NIST.

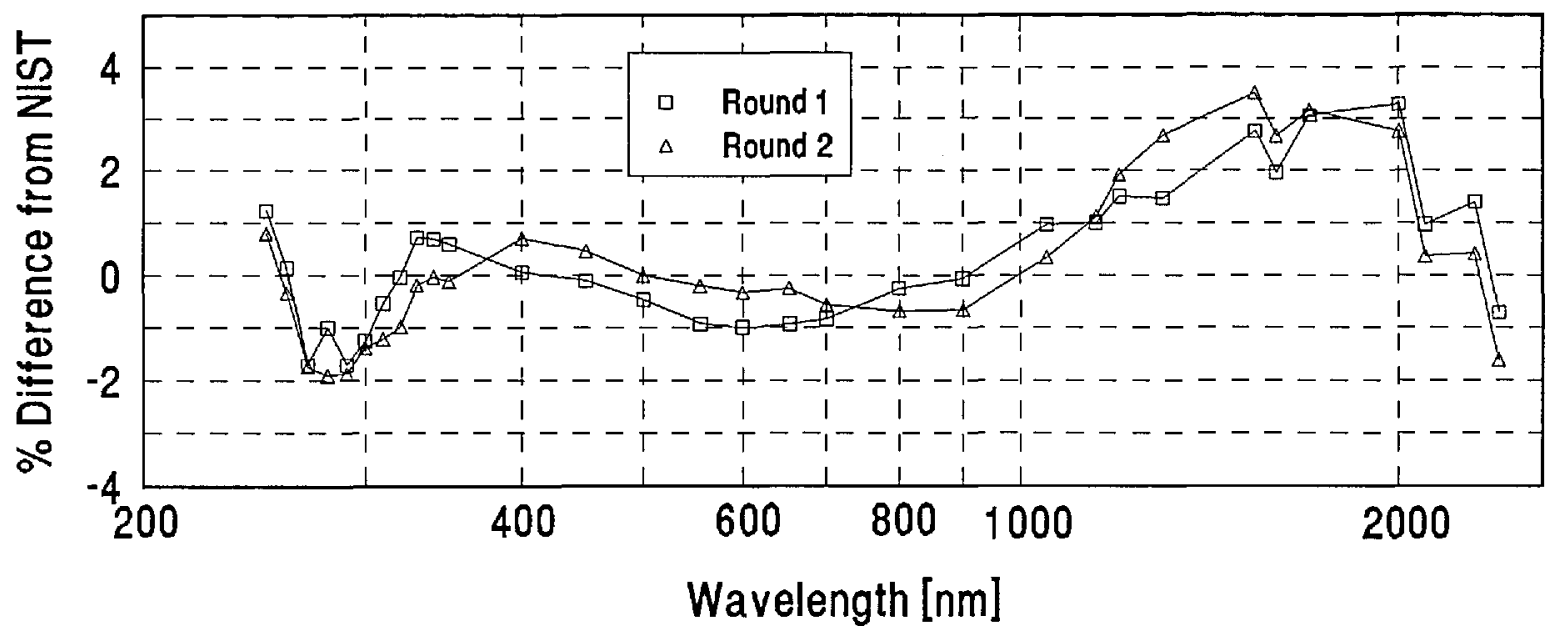

Figure 8. PTB lamp F28 percent difference from NIST.

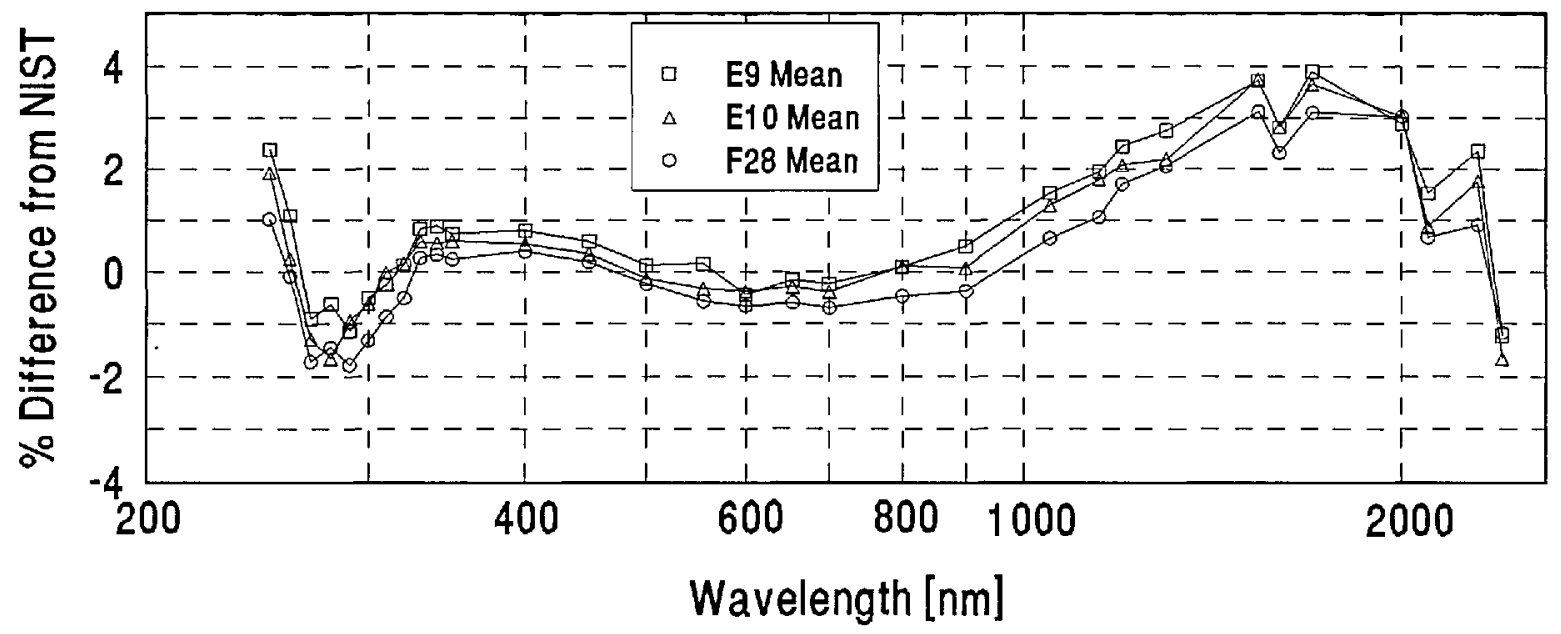

Figure 9. PTB percent difference from NIST. 


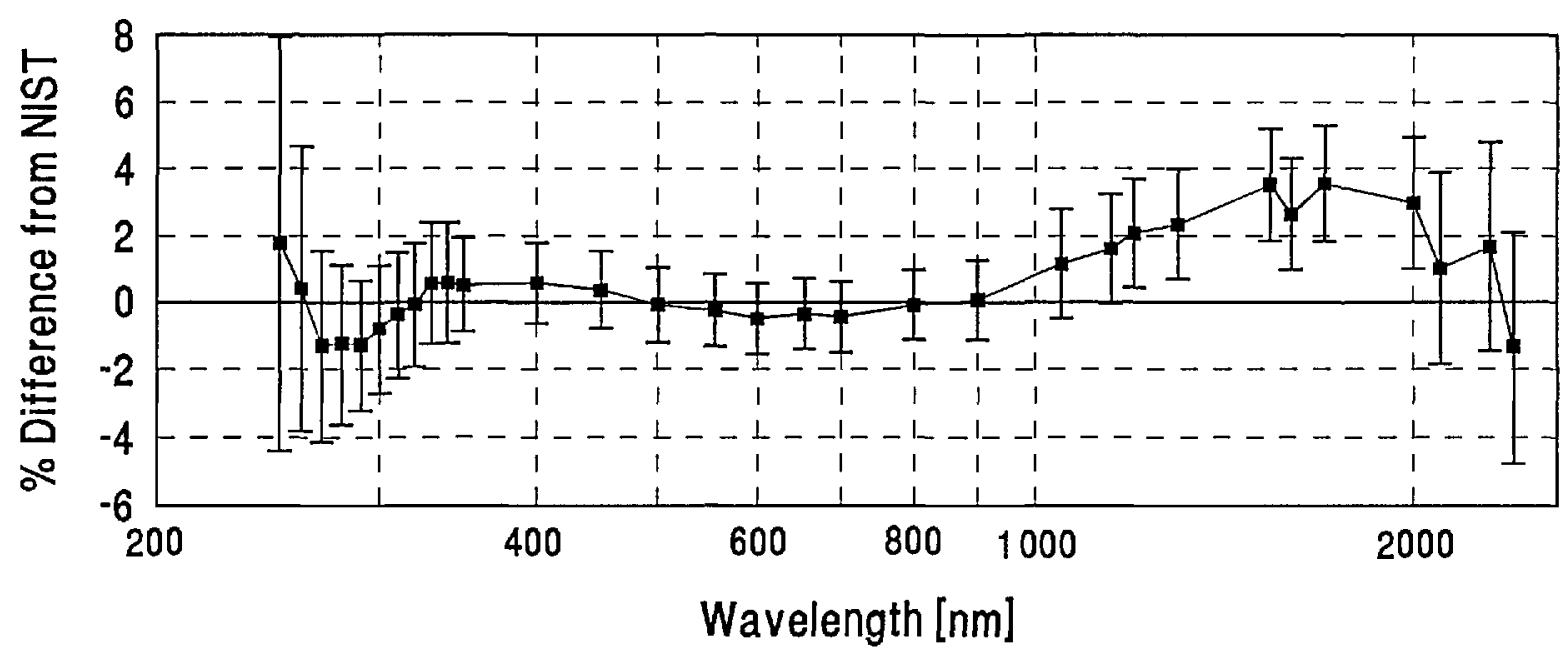

Figure 10. PTB grand-mean percent difference from NIST and combined PTB/NIST uncertainty.

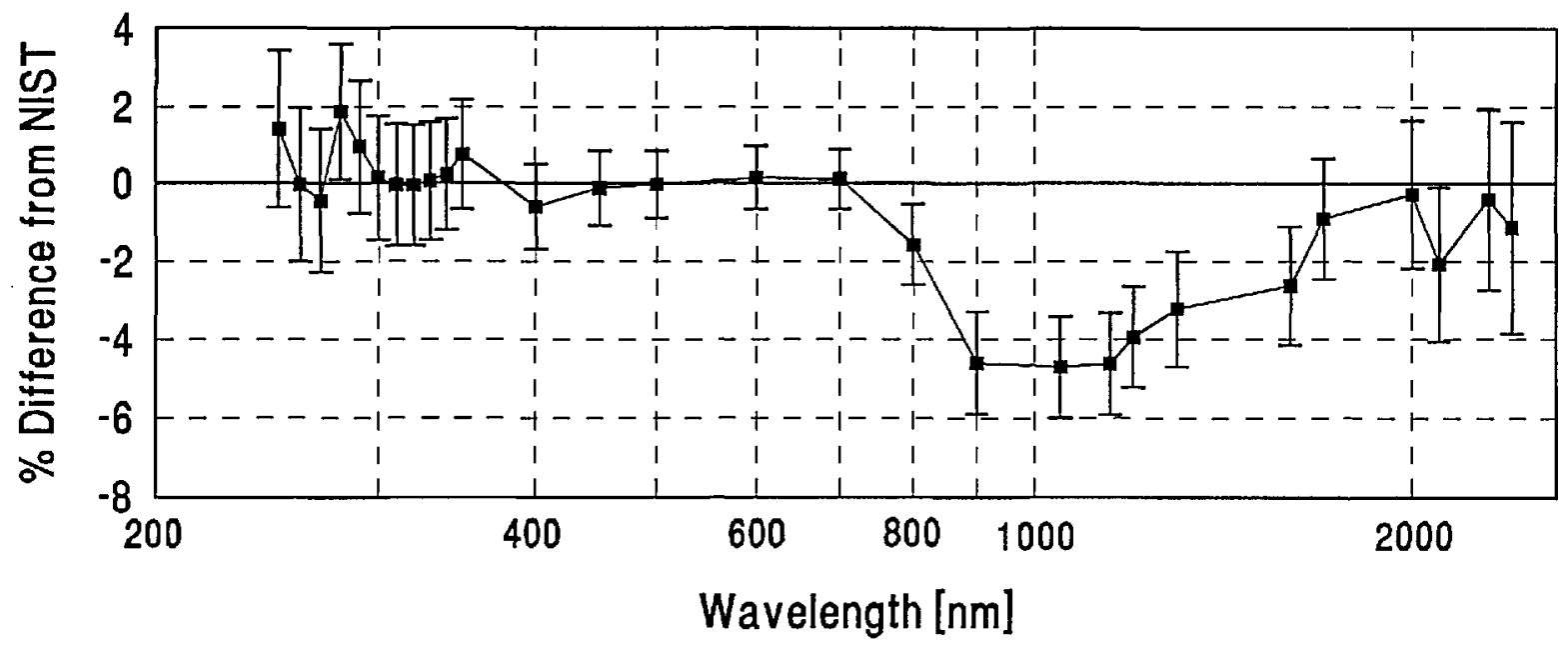

Figure 11. CSIRO grand-mean percent difference from NIST and combined CSIRO/NIST uncertainty.

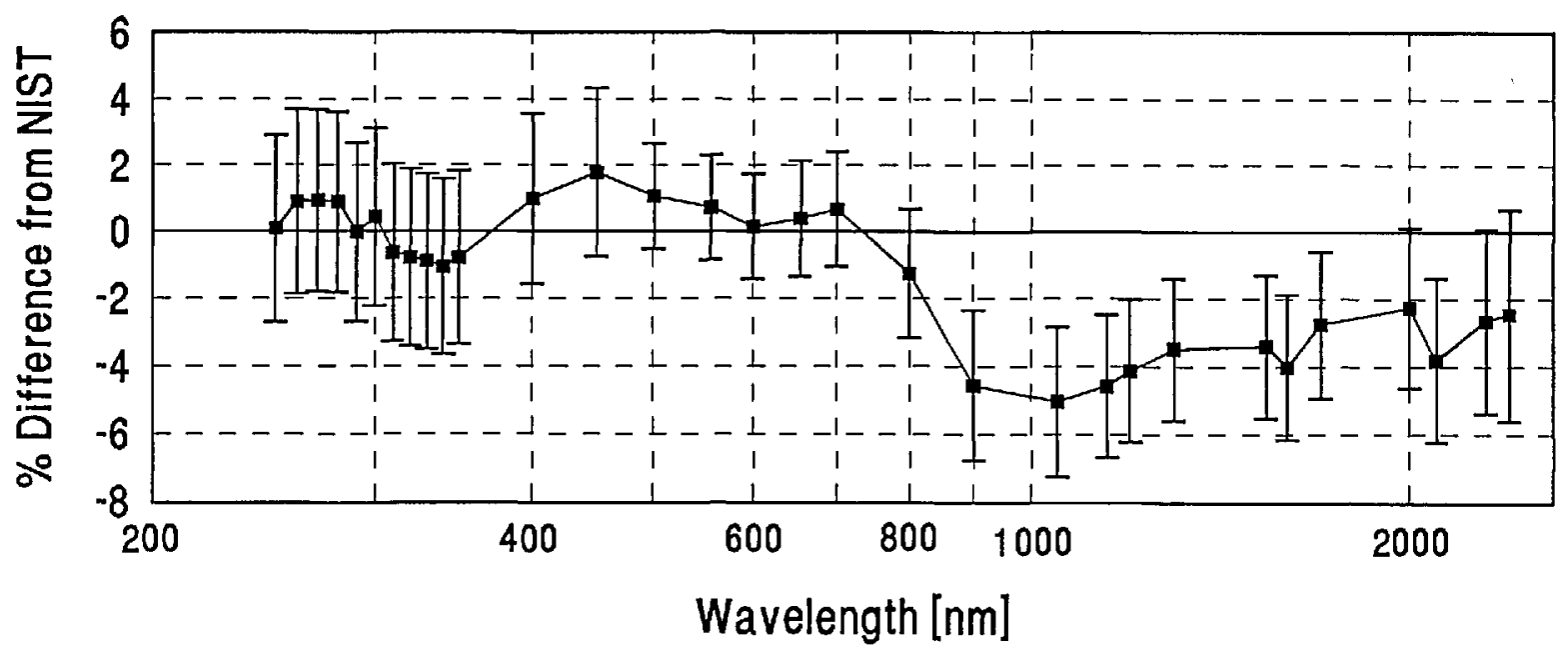

Figure 12. ETL grand-mean percent difference from NIST and combined ETL/NIST uncertainty. 


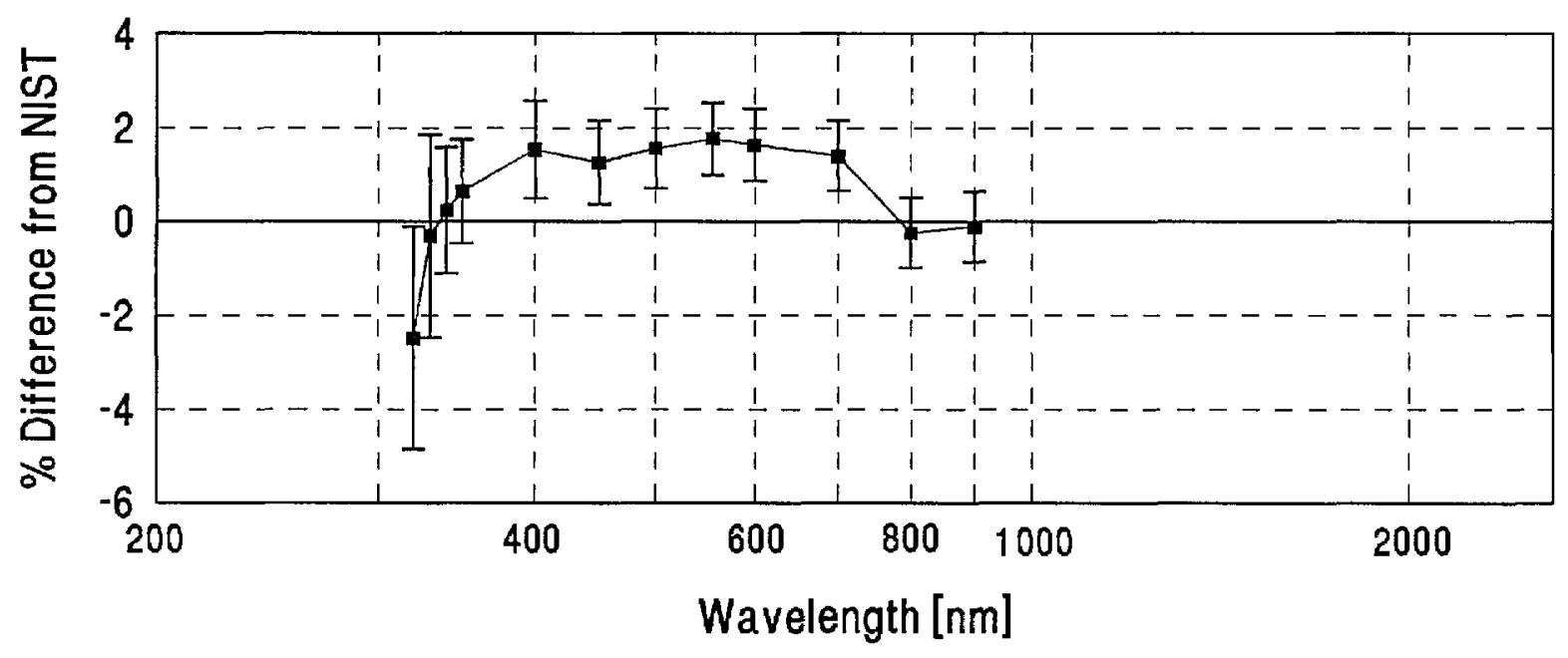

Figure 13. INM grand-mean percent difference from NIST and combined INM/NIST uncertainty.

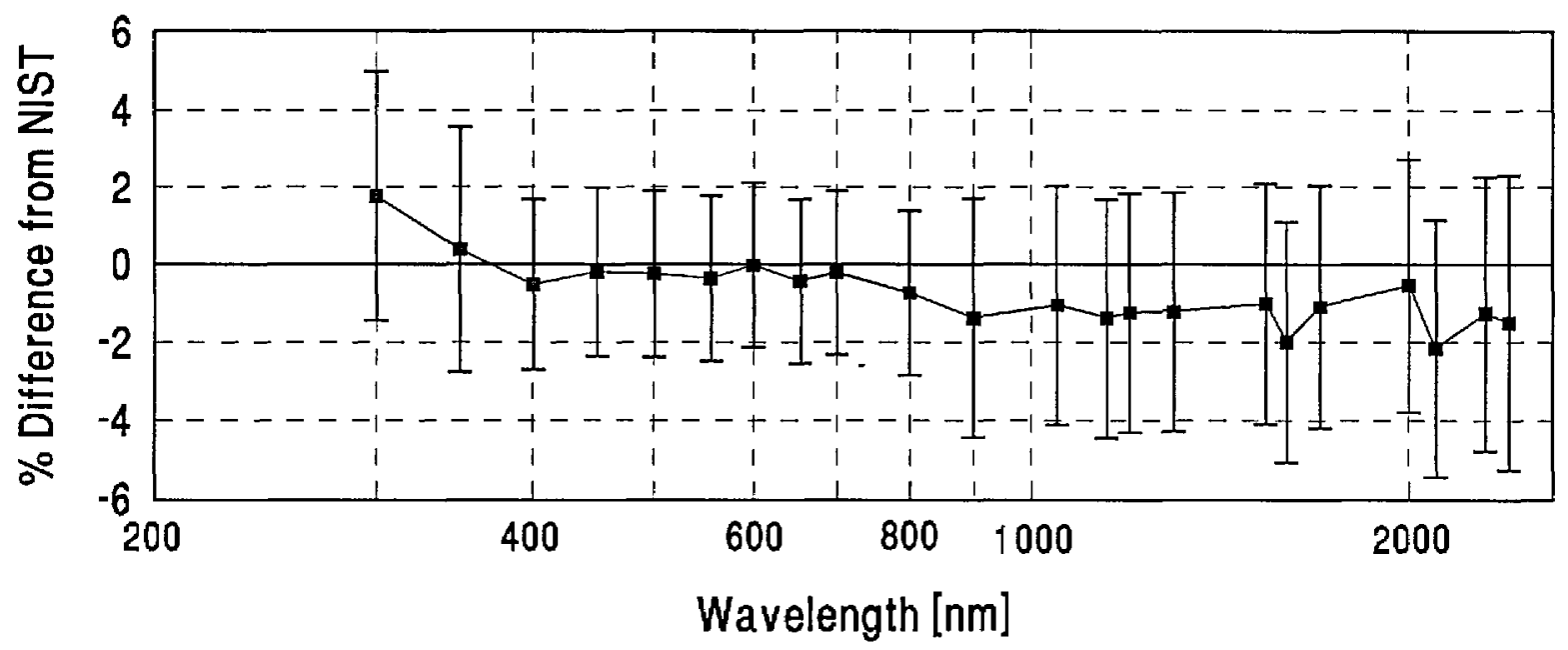

Figure 14. IOM grand-mean percent difference from NIST and combined IOM/NIST uncertainty.

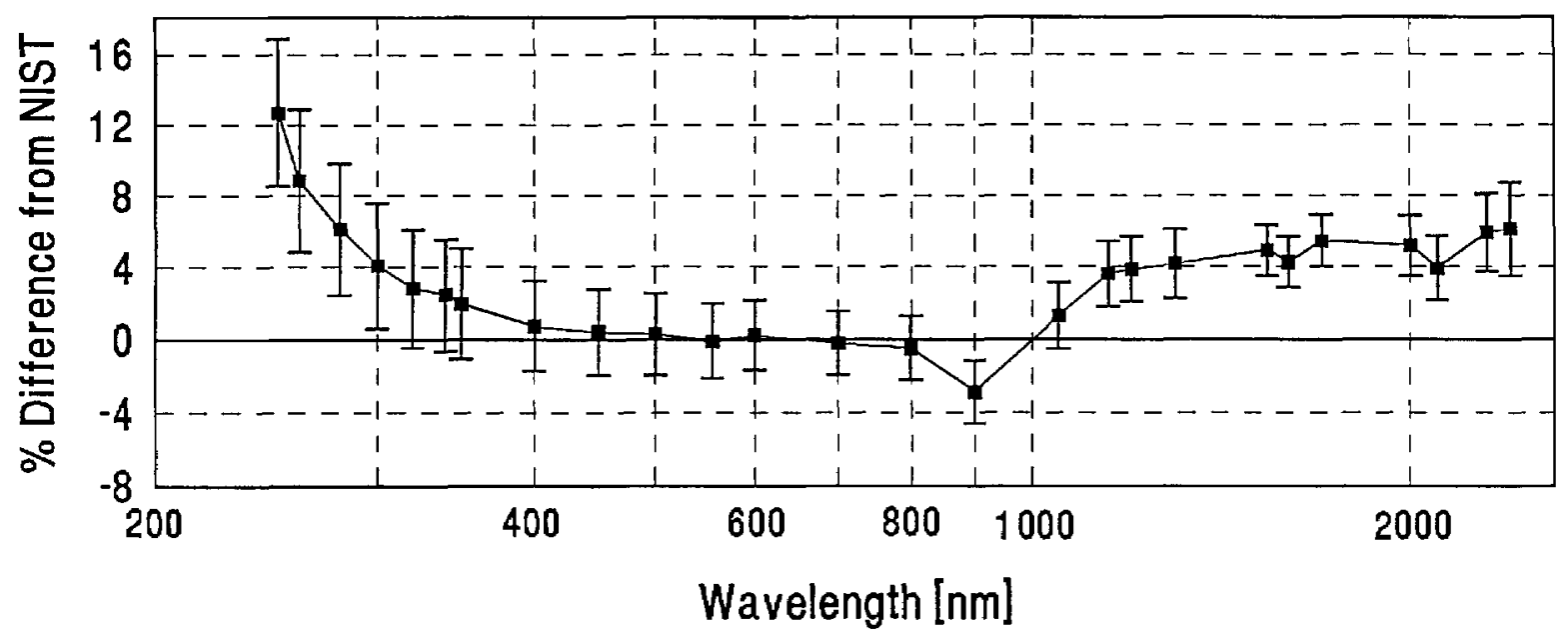

Figure 15. NIM grand-mean percent difference from NIST and combined NIM/NIST uncertainty. 


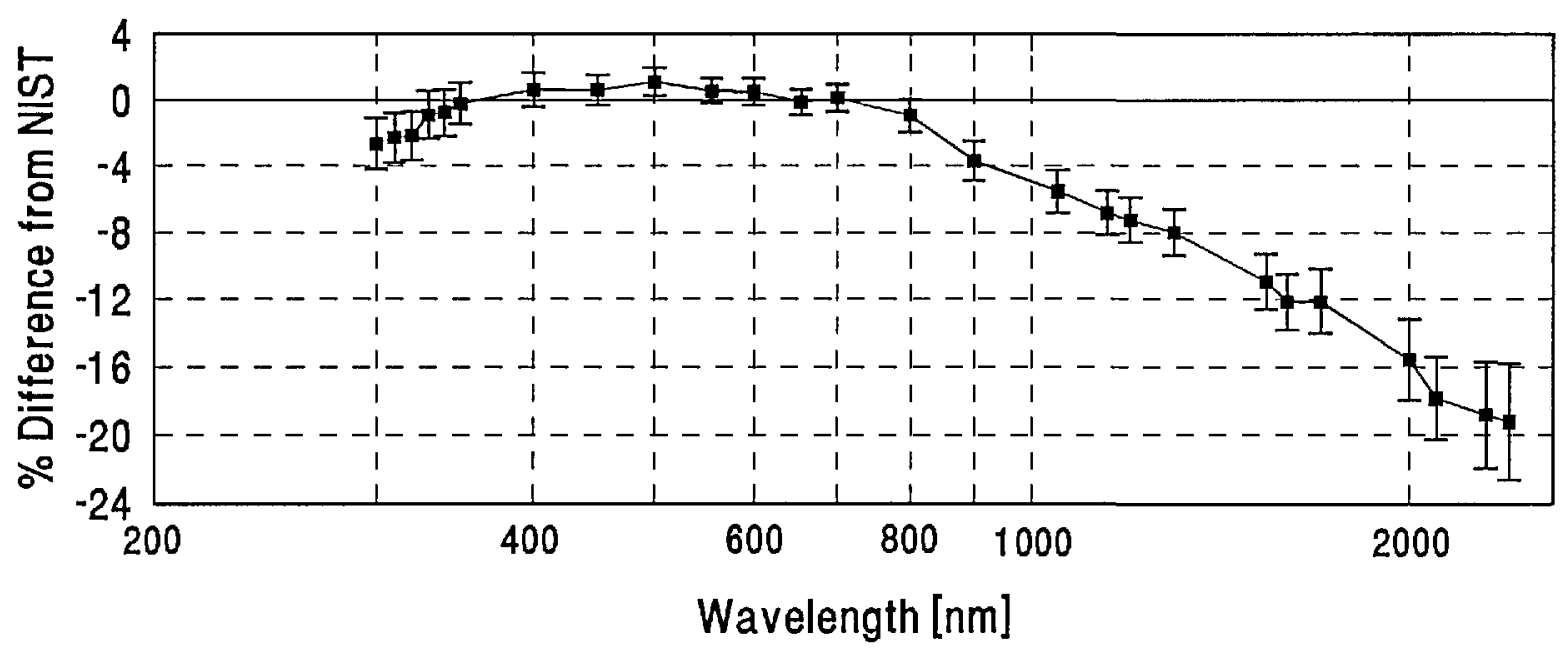

Figure 16. NPL grand-mean percent difference from NIST and combined NPLNIST uncertainty.

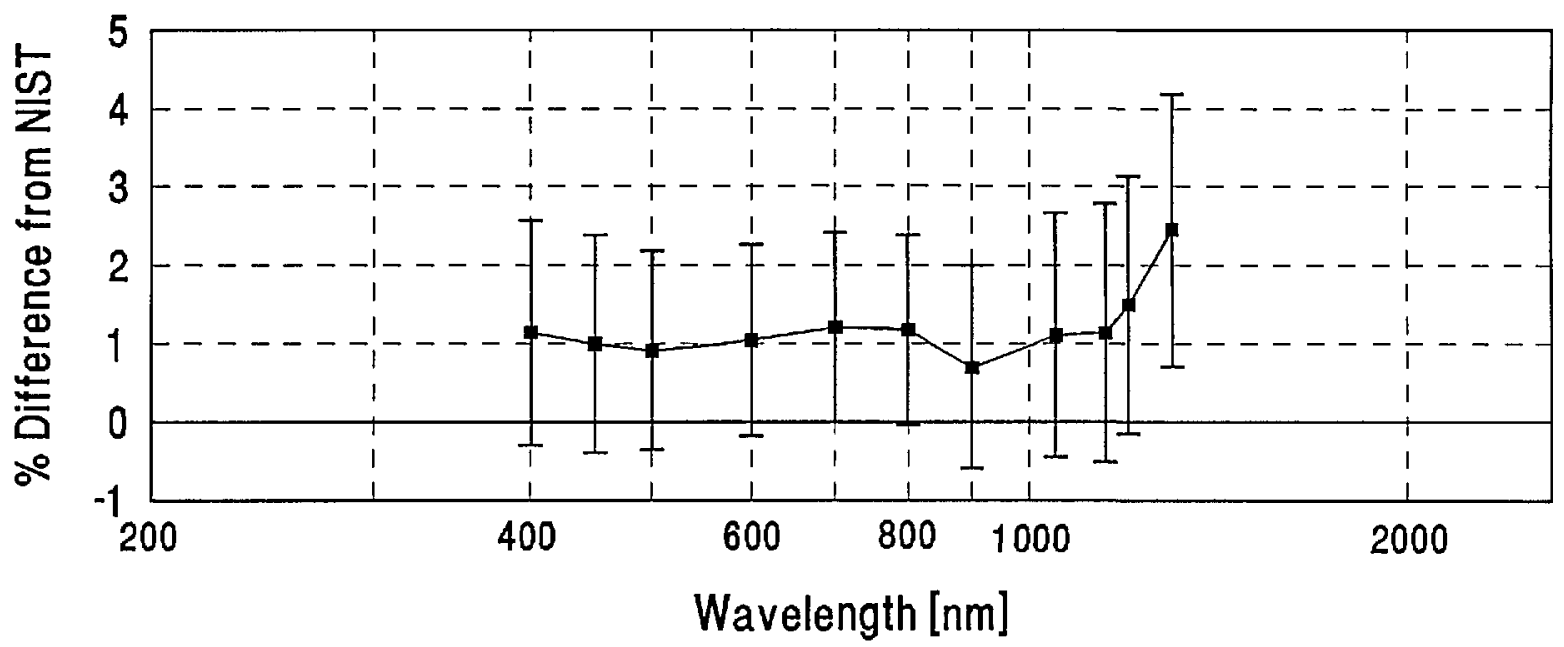

Figure 17. DPT grand-mean percent difference from NIST and combined DPT/NIST uncertainty.

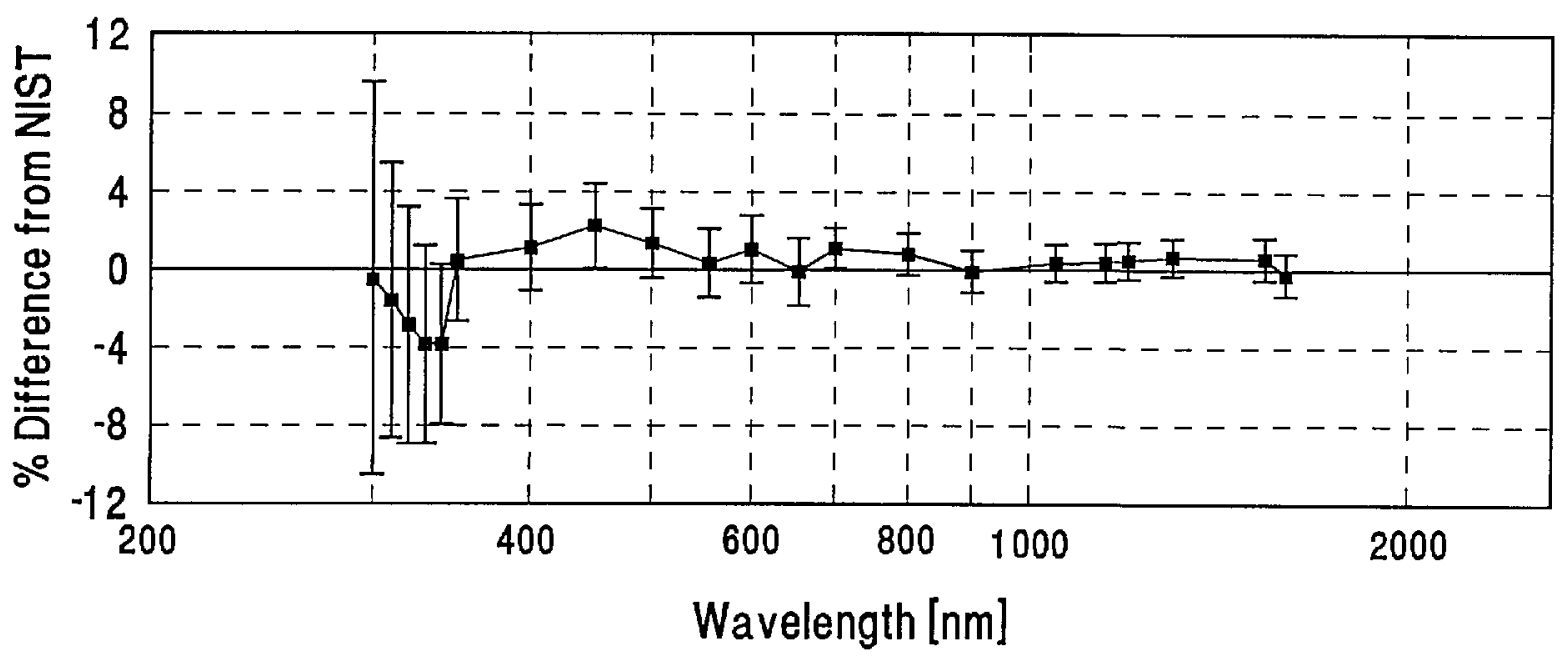

Figure 18. NRC grand-mean percent difference from NIST and combined NRC/NIST uncertainty. 


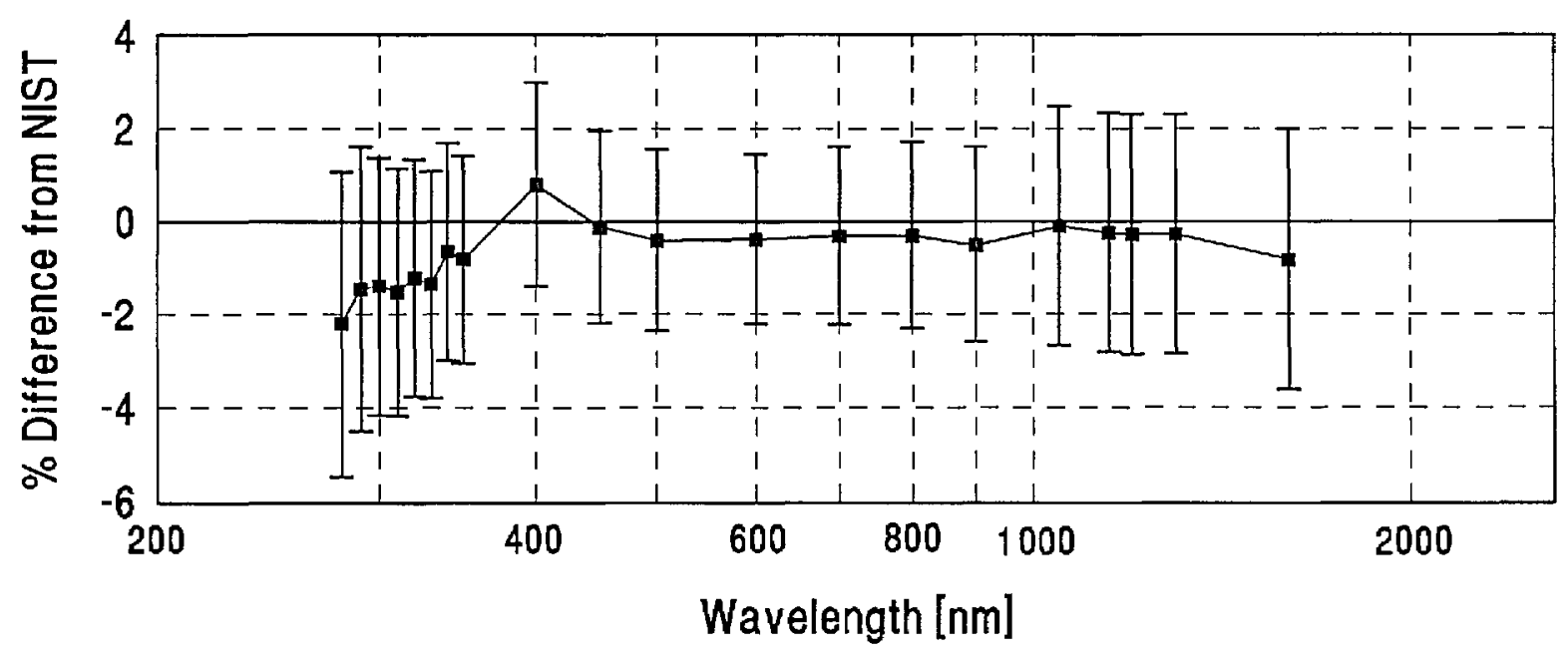

Figure 19. OMH grand-mean percent difference from NIST and combined OMH/NIST uncertainty.

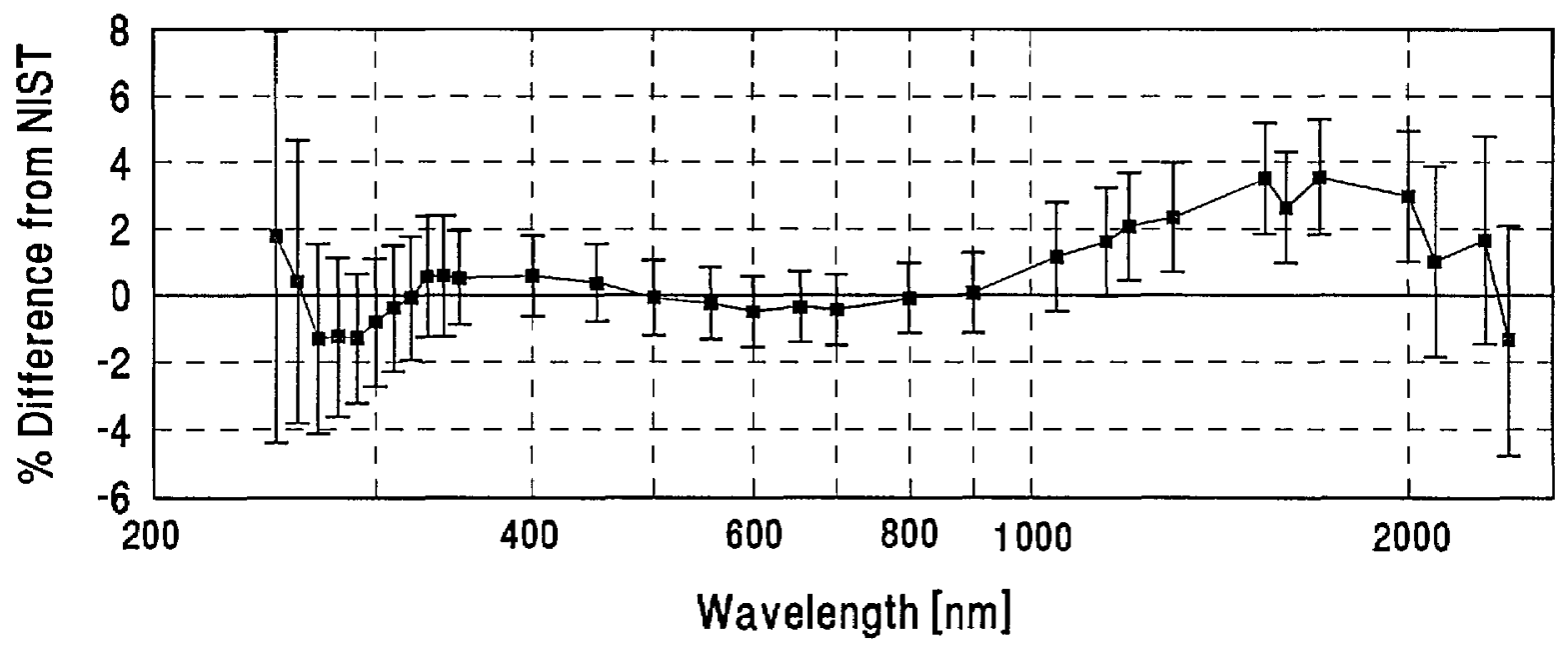

Figure 20. PTB grand-mean percent difference from NIST and combined PTB/NIST uncertainty.

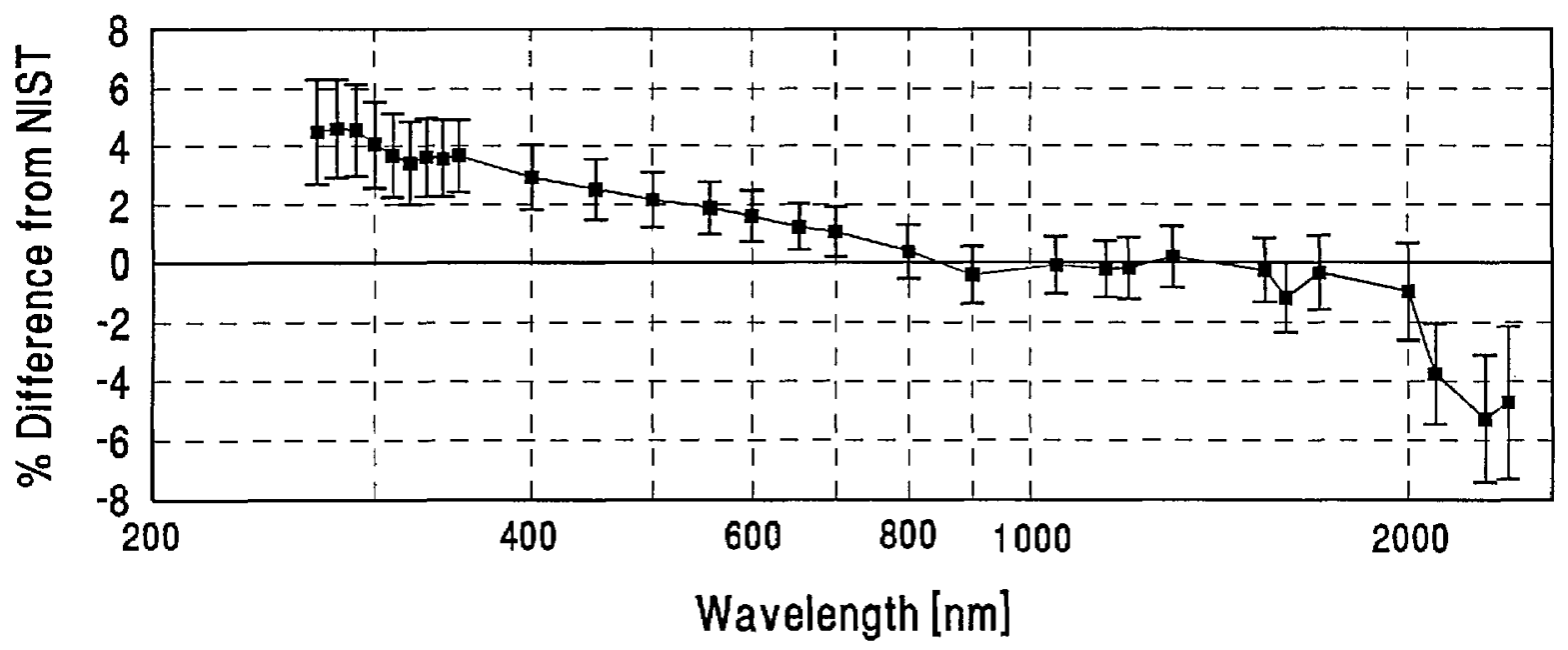

Figure 21. VNIIOFI grand-mean percent difference from NIST and combined VNIIOFI/NIST uncertainty. 


\section{References}

[1] Comité Consultatif de Photometrie et Radiometrie, Report of 11th Session. BIPM, Sevres Cedex, France (1986).

[2] Comité Consultatif de Photometrie et Radiometrie, Report of 12th Session. BIPM, Sevres Cedex, France (1990).

[3] M. Suzuki and N. Ooba, Metrologia 12, 123 (1976).

[4] T. M. Goodman and J. R. Moore, Report on the Development of a Tungsten-Halogen Lamp for Use as a Sccondary Standard. BCR Contract \#760/1/000/059/82/2-BCRUK(30). NPL, Teddington, U.K. (1987).

[5] J. H. Walker, R. D. Saunders, J. K. Jackson, and D. A. McSparron, Spectral Irradiance Calibrations. NBS Special Publication 250-20. U.S. Government Printing Office, Washington, DC (1987).

[6] H. Preston-Thomas, Metrologia 27, 3 (1990).

[7] K. D. Mielenz, R. D. Saunders, A. C. Parr, and J. J. Hsia, J. Res. Natl. Inst. Stand. Technol. 95, 621 (1990).

About the authors: James Walker is an optical physicist in the Radiometric Physics Division at NIST. Robert Saunders, an optical physicist, is presently the group leader of the Thermal Radiometry Group of the Radiometric Physics Division. John Jackson is responsible for making measurements in the Facility for $\mathrm{Au}$ tomated Spectroradiometric Calibrations (FASCAL) in the Radiometric Physics Division. Klaus Mielenz, a physicist, is the retired Chief of the Radiometric Physics Division. 